\title{
INTERPRETATIONS OF SHALLOW SEISMIC-REFRACTION SURVEYS PERFORMED AT EIGHT PROPOSED DEEP CRUSTAL STUDIES REFRACTION SHOT POINTS IN DEATH VALLEY NATIONAL MONUMENT, CALIFORNIA
}

By

Robert D. Luzitano

Prepared by the

U.S. GEOLOGICAL SURVEY

for the

\section{DEATH VALLEY NATIONAL MONUMENT HEADQUARTERS \\ NATIONAL PARK SERVICE \\ U.S. DEPARTMENT OF THE INTERIOR}
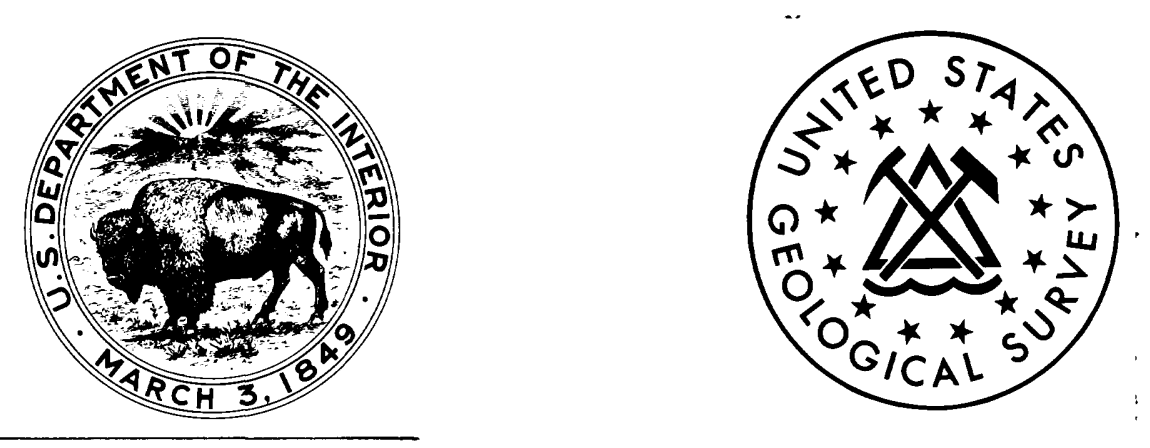

\section{OPEN-FILE REPORT 88-508}

This report is preliminary and has not been reviewed for conformity with U.S.Geological Survey editorial standards (and stratigraphic nomenclature). Any use of trade names is for descriptive purposes only and does not imply endorsement by the USGS.

Menlo Park, California 1988 


\title{
UNITED STATES DEPARTMENT OF THE INTERIOR GEOLOGICAL SURVEY
}

\author{
Interpretations of Shallow Seismic-Refraction Surveys Performed at \\ Eight Proposed Deep Crustal Studies Refraction Shot Points in \\ Death Valley National Monument, California
}

Robert D. Luzitano ${ }^{1}$

Open-File Report 88-508
Prepared for Death Valley National Monument Headquarters
National Park Service
U.S. Department of the Interior

This report is preliminary and has not been reviewed for conformity with U.S. Geological Survey editorial standards (and stratigraphic nomenclature). Any use of trade names is for descriptive purposes only and does not imply endorsement by the USGS

${ }^{1}$ USGS, Menlo Park, California 


\section{Table of Contents}

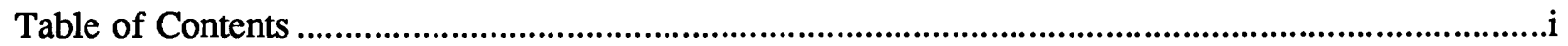

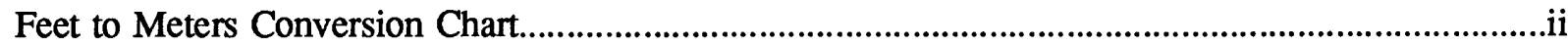

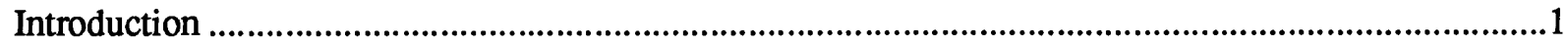

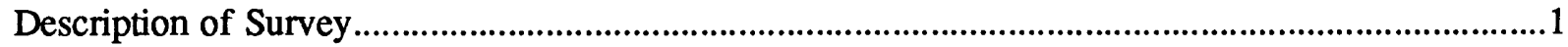

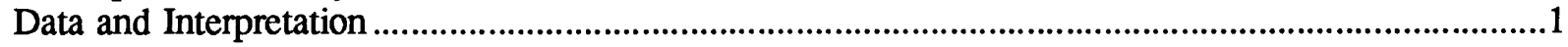

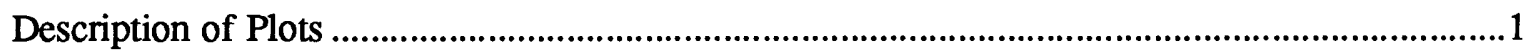

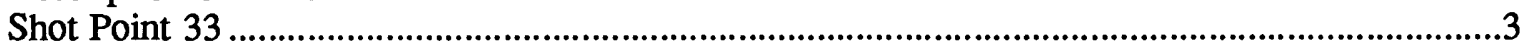

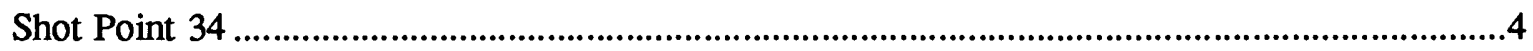

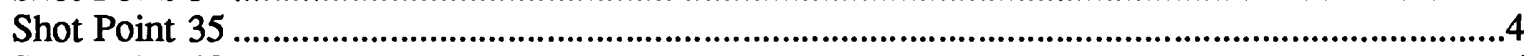

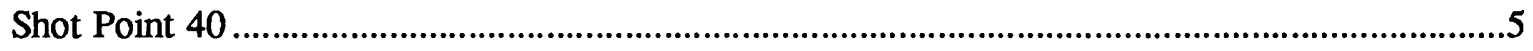

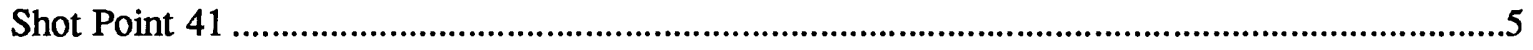

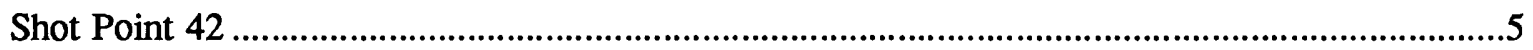

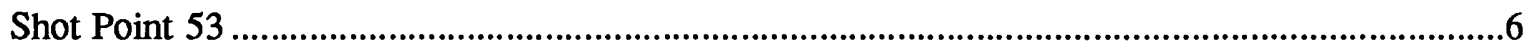

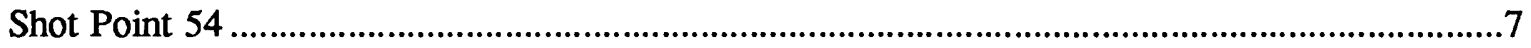

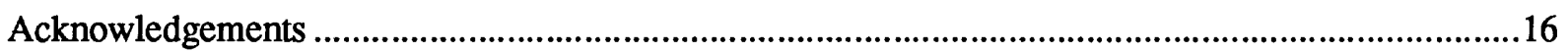

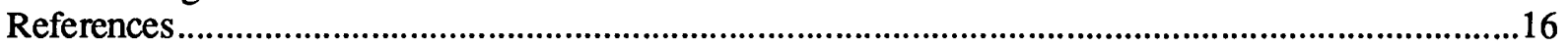

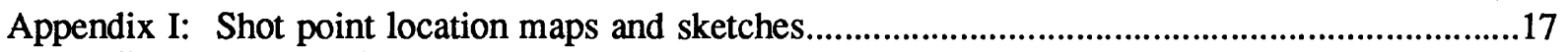

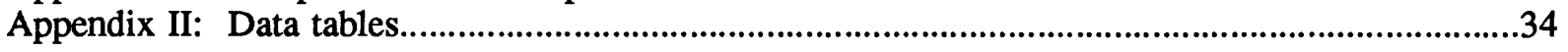

\section{Table of Figures}

Figure

1. General shot point location map of Death Valley. ................................................................2

2. Oscilloscope display of the waveform and picking cursor. ..........................................................

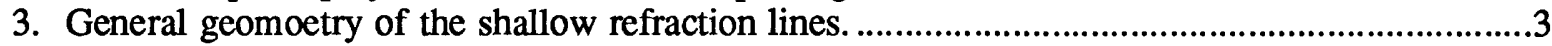

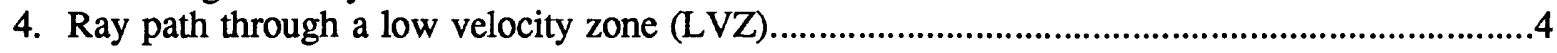

\section{Travel Time Plots and Interpreted Models}

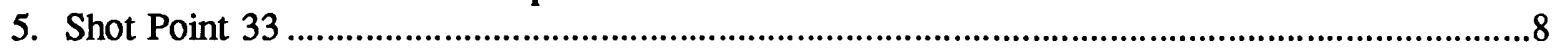

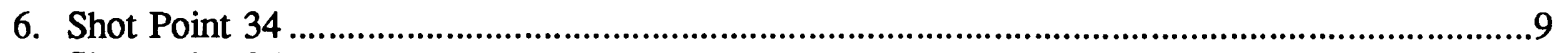

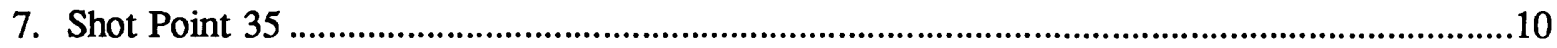

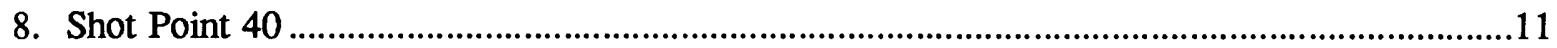

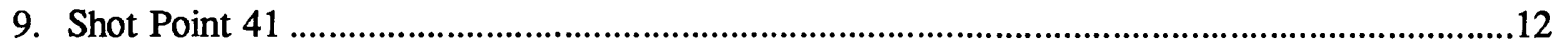

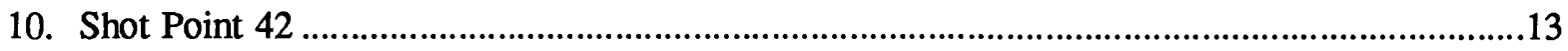

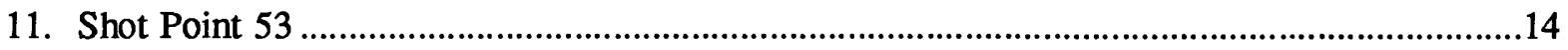

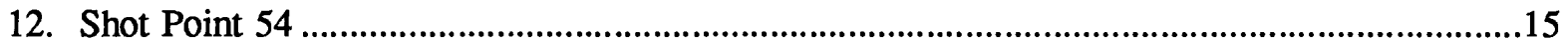


This report was written primarily to satisfy an environmental assessment requirement for Death Valley National Monument. For the benefit of the National Park Service, this report uses the english measuring system. A conversion chart between feet and meters is given below.

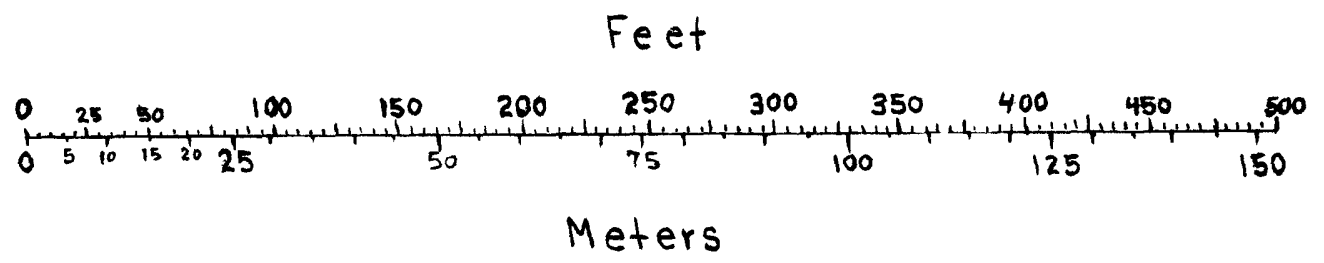




\section{INTRODUCTION}

During January $25-29,1988$, the U. S. Geological Survey performed eight shallow seismic refraction surveys in Death Valley National Monument, California. The purpose of this study was to identify the water table geometry at proposed drill sites to satisfy an environmental assessment requirement of the National Park Service. The drill sites will be shot points for a large scale seismic refraction experiment to image the crust and upper mantle in the Death Valley area. The eight proposed shot points belong to three different refraction lines traversing northern and central Death Valley (Figure 1). This report presents the shallow refraction data and its interpretation.

\section{DESCRIPTION OF SURVEY}

Two Bison refraction systems were used to collect the data, the 1580 and the $1575 \mathrm{~B}$, six and one channel models respectively. Both systems use a sledge hammer and metal plate as a source. An inertial switch near the hammer head initiates recording by a standard industry geophone when the hammer strikes the plate on the ground. A series of hammer strikes at the same location may be stacked in memory to enhance the signal. The waveform is displayed by an oscilloscope and arrival times are picked using a cursor - digital LED combination (Figure 2). Except for some photographs, no permanent record of the waveform is produced. Therefore, the field data consists only of arrival times, displayed as travel time plots.

Most of the refraction lines were oriented down slope in drainage channels to minimize surface undulations that would add more scatter to the data (see location maps in Appendix 1). Minimum scatter made identifying cross over points easier in the field. This allowed us to collect additional data around the cross over points to better constrain the travel time curve. A line length of 300 feet was chosen (except for shot point 53 which was 330 feet) to penetrate the water table depth expected to be within about 80 feet subsurface in most cases. The lines were hammered in both forward and reverse directions to define any dipping interface. Hammer spacing was primarily 30 feet with secondary hammer points at 10,20, and 45 feet from the geophone at the end of the line to constrain the upper-most layer (Figure 3). Additional hammer points were added, where necessary, to help define crossover points, and better constrain scattered data. Abrupt elevation changes along the line, such as a levee, were noted, but this was only a concern at shot point 33 (SP-33). Approximate elevation and slope of a survey line were estimated from $15^{\prime}$ topographic quadrangles with an accuracy of at least \pm 2 feet for a slope over a 300 foot line.

A number of factors common in the Death Valley environment can make interpretation difficult and the water table elusive to seismic refraction. Many of the proposed shot points are located on alluvial fans (containing large boulders and irregular interfaces at depth) which induces scatter in the travel time curves. Wind can also induce scatter by creating noise in the waveform, which make picking arrivals uncertain, but this was rarely a problem. Another problem is that relatively thin calcareous, or evaporite layers may exist in the fans or in the valley floor. Such a layer has a faster velocity than the expected water saturated alluvium velocity of about 3300 - $5200 \mathrm{feet} / \mathrm{sec}$ (Duguid, 1968; Cummings, 1979; Tinsley, personal communication). This unusually faster layer will hide an underlying slower layer, since no refracted energy is returned from the top of a low velocity zone (Figure 4). A similar velocity problem arises in the valley floor when the faster velocity lake sediments are encountered. Although the water table may occur within, or coincide with the lake sediments, the water table could not be recognized by velocity. Either case makes the water table a hidden layer occurring somewhere below the top of the faster material.

\section{DATA AND INTERPRETATION}

\section{Description of Plots}

The plots in Figures 5 - 12 display the travel time curves fit to the forward and reversed data, and the interpreted models. Each branch is extrapolated back to its intercept time. Travel time curves are labeled with their apparent velocities (V1, V2, etc.) to the nearest $100 \mathrm{ft} / \mathrm{sec}$. The interpreted model 


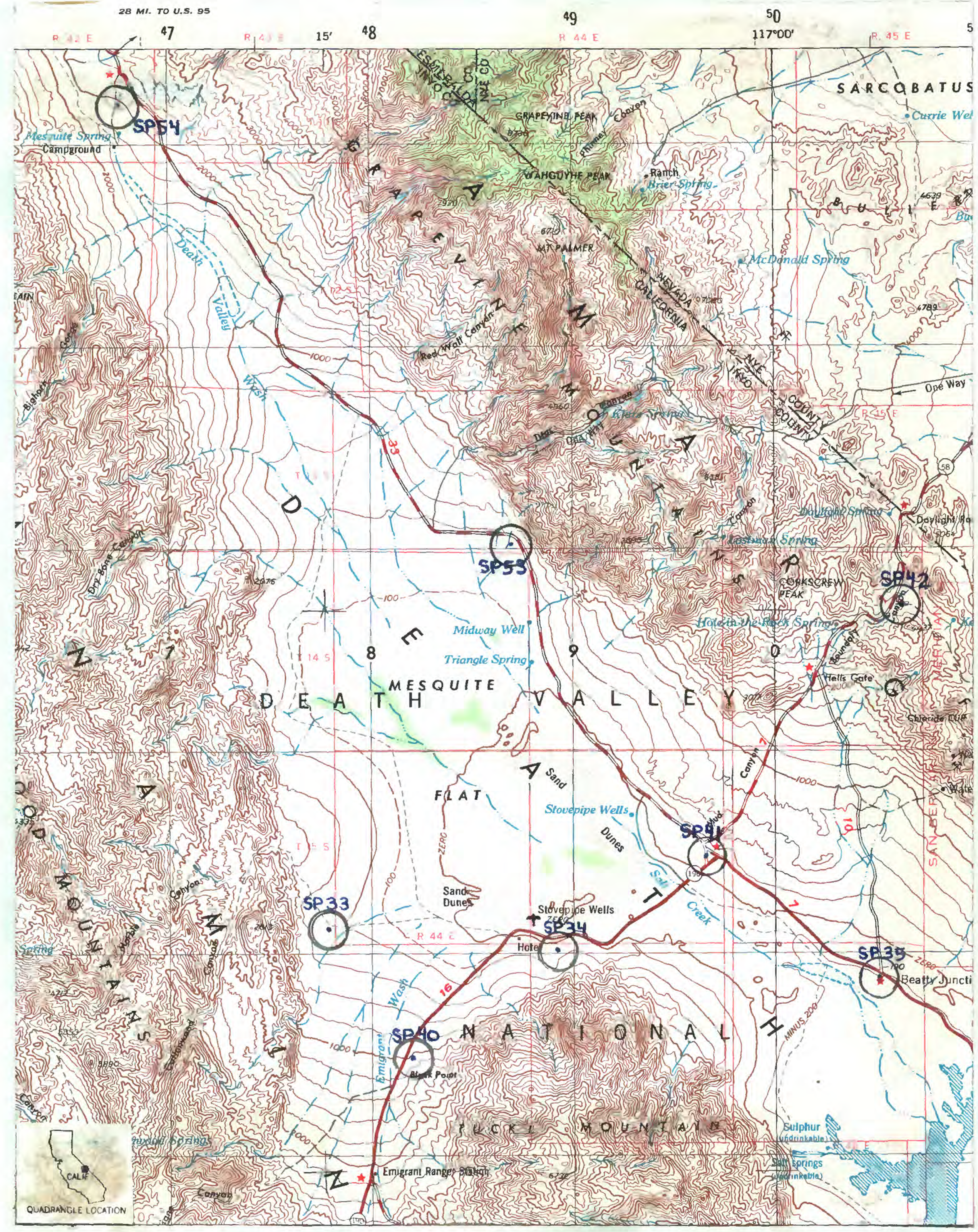

Figure 1. General location map of shot points (SP) 33, 34, 35, 40, 41, 42, 53,54 . 
below the travel time plot shows the resulting velocities. Vertical exageration on the models is 4:1, except for SP-42 and SP-54 which is 2:1. Depths (D1, D2, etc.) to the nearest foot below the surface are calculated from the intercept times of the travel time curve.

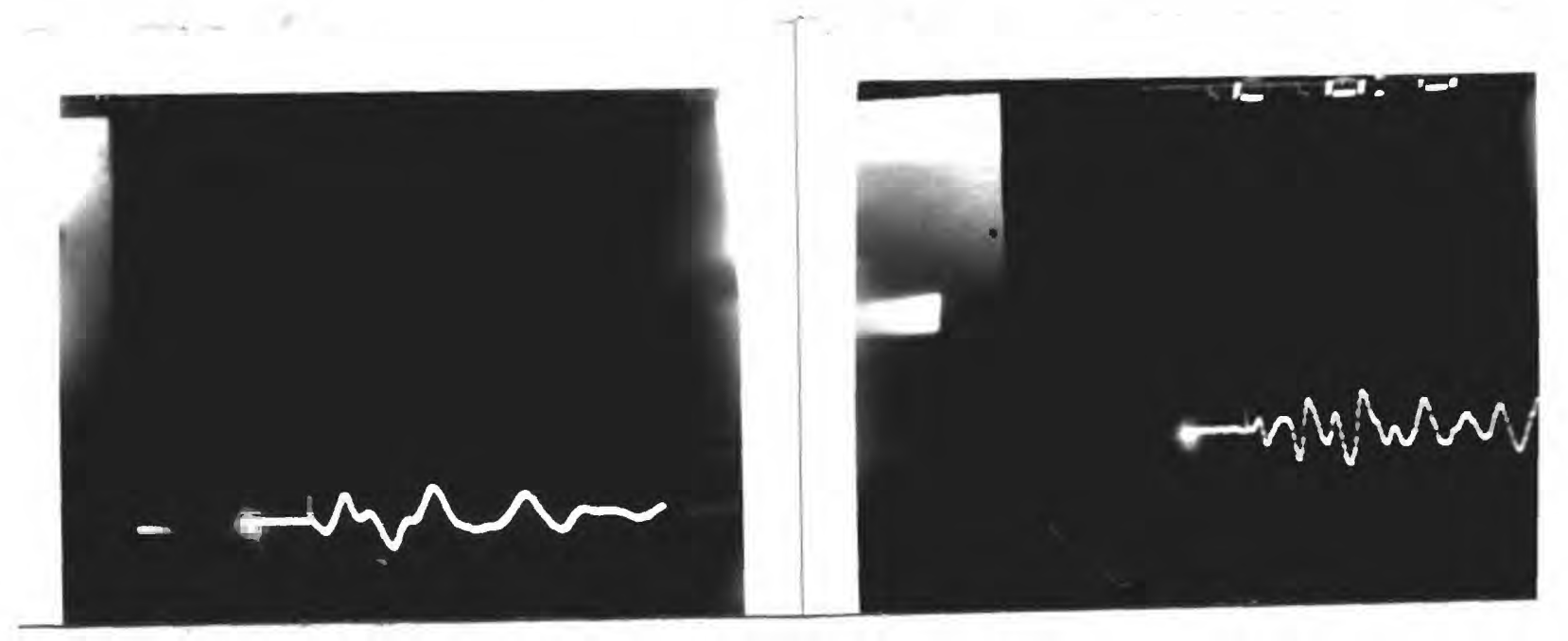

Figure 2. Example of first arrival picks from the Bison. Picks are from SP-42 at hammer points 1.2 (left) and 5-A (right). Part of the LED is visible for $5 \mathrm{~A}$ and the picking cursor is visible at both picks.

\begin{tabular}{|c|c|c|c|c|c|c|c|c|c|c|c|c|c|c|c|c|}
\hline \multicolumn{17}{|c|}{ Hammer Point Location Numbers } \\
\hline 1 & 1.1 & 1.2 & 2 & 21 & 3 & 4 & 5 & 6 & 7 & 8 & 9 & 9.1 & 10 & 10.1 & 10.2 & 11 \\
\hline $\mathbf{x}$ & $x$ & $\mathbf{x}$ & $x$ & $\mathbf{x}$ & $\mathbf{x}$ & $\mathbf{x}$ & $\mathbf{x}$ & $\mathbf{x}$ & $\mathbf{x}$ & $\mathbf{x}$ & $\mathbf{x}$ & $\mathbf{x}$ & $\mathbf{x}$ & $\mathbf{x}$ & $\mathbf{x}$ & $\mathbf{x}$ \\
\hline A & & & & & & & & & & & & & & & & B \\
\hline 0 & & & 30 & & 60 & 90 & 120 & 150 & 180 & 210 & 240 & & 270 & & & 300 \\
\hline & & & & & & & & ance & & & & & & & & \\
\hline
\end{tabular}

Figure 3. General geometry of the shallow refraction lines showing hammer point location numbers and distance in feet. The geophones are located at A and B. Additional hammer points are added when required to better constrain scatter and crossover points.

\section{Shot Point 33}

This site is located at the bottom of an alluvial fan at about 230 feet elevation. The stake is located about 140 feet southwest of the dirt road that leads from Stovepipe Wells Hotel to Cottonwood Canyon (Figure AI-1, AI-2 in Appendix 1). The corral shown in figure AI-2 no longer exists. The refraction line is centered about 10 feet southwest of the stake and trends N50W. The northwest end of the line drops off a levey onto the dirt road. A couple of small washes are traversed towards the southeast end of the line (Figure 5B).

The data are fairly scattered, especially the last 90 feet of the reversed line (Figure 5A). Some of the scatter may be due to the somewhat irregular surface. However, enough data were collected to obtain a reasonable fit with a simple travel time curve. The last 60 feet of the forward line is fairly well constrained, therefore the reversed curve is forced to reciprocate with the forward curve at about $70 \mathrm{msec}$. Two layers were obtained, the second layer, only about 10 feet below the surface, has a velocity of about $5150 \mathrm{ft} / \mathrm{sec}$ (Figure $5 \mathrm{~B}$ ). This layer may be a thick sandy sequence, or possibly sand and gravel with a clay matrix, both of which might include the water table. The interface is fairly flat 
across the line, generally following the slope of the topography. Based on this model, the water table may coincide with the top of this layer, or below an estimated imaging depth of about 80 feet. The 130 foot drill hole is expected to encounter the water table.

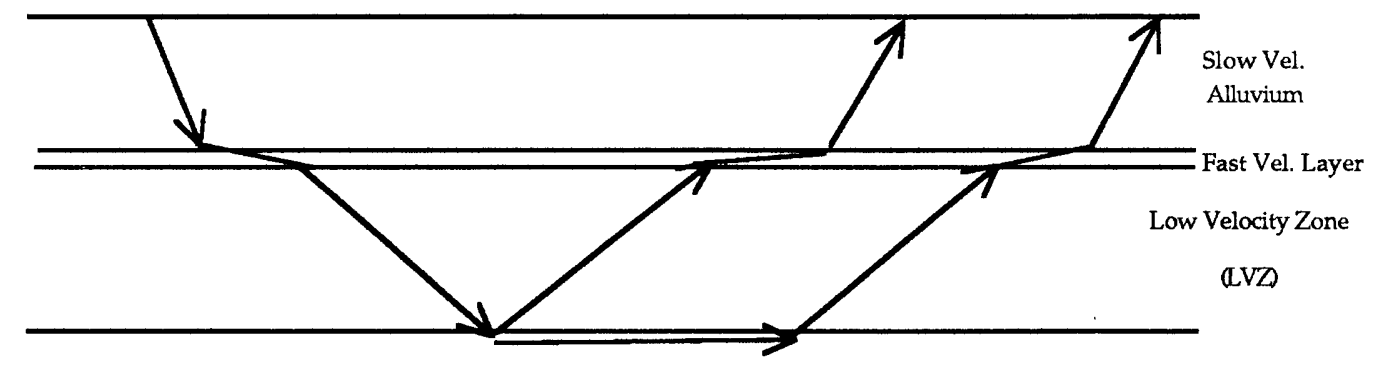

Figure 4. Seismic energy is bent downward at the top of the LVZ, therefore no energy is returned to the surface by this interface. The LVZ may even be the water table, yielding no water table refraction. The fast velocity layer may be an evaporite or calcareous zone.

\section{Shot Point 34}

Shot point 34, at an approximate elevation of 100 feet, is staked in a major wash that crosses the dirt road leading to Grotto Canyon in Tucki Mountain. The refraction line runs down the wash, crossing the dirt road 0.2 miles south of Highway 190 in the middle of a large alluvial fan (Figures AI-3, AI-4). Except for crossing the road, the survey line traverses a relatively smooth surface trending N7W.

Except for a couple of points the data is quite smooth and is easily fit with the travel time curves (Figure 6A). Some scatter occurs at the second reversed cross over point, making the existence of the very short second branch somewhat questionable. However, the reversed data is fit best with three branches, which are required in order to correlate with the more certain forward case. Both forward and reverse data reciprocate well. This three layer case may include water-bearing alluvium, which likely is not the water table. The second layer may consist of packed unconsolidated fan alluvium, with the first layer being a gradient of increasing compaction with depth. The interface at 5 to 6 feet depth (Figure 6B) probably exists only seismically and not as a stratigraphic horizon to be noticed during drilling. At $4250 \mathrm{ft} / \mathrm{sec}$ the third layer is in the middle range of the expected water table velocity. However, this second interface is fairly shallow for water table in this area (Buono and Packard, 1982) and dips from a depth of 10 feet at the south to 18 feet at the north. A longer survey line would possibly reveal a fourth layer in the expected velocity range below 80 feet. Most likely, this third layer contains some residual water from runoff due to recent storms, with the primary water table below 80 feet.

\section{Shot Point 35}

Two hundred feet southwest of Highway 190 at Beatty Junction in a broad wash, a flagged bush marks the drilling area (Figures AI-5, AI-6). The refraction line was centered on the drill site, traversing N78W across a mostly flat surface at the toe of an alluvial fan. This location is only about one mile from Salt Creek which enters a large salt flat at about $-230 \mathrm{ft}$ elevation, only about 30 feet below the shot point elevation. Therefore, the 130 foot drill holes are expected to penetrate the water table, although it was not recognized by the refraction survey.

Overall the data quality is good with very little scatter (Figure 7A). The first layer was not defined by hammer points 10 and 20 feet from the geophones as are the other locations. However, the first velocity is estimated in good agreement with the average. The only notably bad pick is the reciprical arrival for the reverse line with an uncertainty of about $\pm 3.5 \mathrm{msec}$. Therefore, the reversed curve is forced to reciprocate with the forward curve at about $80 \mathrm{msec}$. Other somewhat questionable picks are on the forward line at 60 and 150 feet (Figure 7A). The travel time curves fit quite well yielding a 
three layer case. The first layer is probably a velocity gradient, due to compaction with depth, with an average velocity of $1250 \mathrm{ft} / \mathrm{sec}$. Therefore drilling should not show any definite discontinuity at 8 feet as shown in the model (Figure 7B). Alluvial fan material, similar to the first layer but more consolidated, probably make up the second layer. Underlying the fan material at 28 to 30 feet should be lake sands and clays and possibly evaporites with an average velocity of $6800 \mathrm{ft} / \mathrm{sec}$. The water table velocity is hidden, probably within the thick layer of lake sediments. The water table probably occurs at least 30 feet and possibly 100 feet subsurface.

\section{Shot Point 40}

Shot point 40, at approximately 1030 feet elevation, is staked 400 feet south of Highway $190,5.3$ miles west of Stovepipe Wells Hotel (Figures AI-7, AI-8). This site is in a 4 foot deep wash on an abandoned road, with the survey line centered at the drill site, trending $\mathrm{N} 25 \mathrm{~W}$ down the wash. The alluvial fan is faulted about $\mathbf{0 . 2}$ miles southeast of the shotpoint at Black Point.

This is some of the cleanest data (very little scatter), however the refraction line was not long enough to reach a water table velocity (Figure 8). Only two layers were resolved within about 80 feet of the surface. A relatively well packed surface layer with little velocity gradient resulted in the first two data points of the forward line fitting very well with the first branch. However, the reversed first branch is a bit scattered (Figure 8A). The reciprical picks have a small difference of about 2 msec, arriving at about $109 \mathrm{msec}$. An average velocity of about $1350 \mathrm{ft} / \mathrm{sec}$ defines the surface layer of sand and gravel wash material. The top of the second layer mostly parrallels the surface with a depth of about 7 feet at the southeast end and 8 feet at the northwest end (Figure 8B). Alluvial fan deposits composed of sand and gravel with boulders probably make up the second layer with a velocity of 3000 $\mathrm{ft} / \mathrm{sec}$. Water table is at least 80 feet subsurface and probably will not be penetrated by the 130 foot drill hole in this region of the fan.

\section{Shot Point 41}

About 0.3 miles south of the junction of the Daylight Pass Highway and the highway leading to Scotty's Castle is shot point 41 (Figure AI-9). The refraction line is centered on a stake located on the west arm of the abandonned highway Y junction with Highway 190 (Figure AI-10). Trending N9W the survey line follows the smooth surface remaining from the striped pavement. At an elevation of about $150 \mathrm{ft}$, the site is situated near the bottom of an alluvial fan.

Overall, the data fit well with a small amount of scatter that persists throughout the data (Figure 9A). Both recipricating picks agree, despite the scatter. Control is not very good for the third reversing branch, but the forward branch is fit with somewhat better control. This lack of control may affect the northem depth to layer 3 by about 5 feet. Both interfaces of the three layer model dip slightly relative to the surface (Figure 9B). The first two layers are very similar to those of SP-34 and SP-40, also located on alluvial fans. The top layer is loose alluvial fan material characterized by an average velocity of about $1550 \mathrm{ft} / \mathrm{sec}$ down to a depth of 6 to $7 \mathrm{feet}$. The second layer should be similar but more consolidated with an average velocity of about $3200 \mathrm{ft} / \mathrm{sec}$. At a depth of about 56 to 59 feet is a 4750 $\mathrm{ft} / \mathrm{sec}$ layer which is almost certainly the water table. This velocity is near the upper limit for water saturated alluvium, but is within the commonly accepted average (Duguid, 1968; Tinsley, personal communication). Also the depth to this third layer agrees with the depth to water found in water wells across the valley around Stove Pipe Wells (Buono and Packard, 1982).

\section{Shot Point 42}

Situated in the Funeral Mountains near Daylight Pass, the dirt access road is 3.5 miles (Criley and Geist, 1987) north of the Beatty-Furnace Creek cutoff (Figure AI-11). The refraction line trends N70E down the dirt road, and is centered about 30 feet south of a stake which is adjacent to the road against an outcrop of lower Paleozoic - upper pre-Cambrian sedimentary rocks (Figure AI-12). The site is in a wash that is a tributary to a larger wash about 50 feet to the south. Outcrop parallels the upper half of the line within about $20 \mathrm{feet}$, while the southern half of the line leaves the road and enters the 
confluence of the two washes, away from the outcrop (Figure AI-12). The line was situated in this manner to obtain the smoothest surface with a straight line. However, due to the change in proximity of the line with the outcrop and the poor data quality, this site was the most complicated to interpret.

Some of the data are very scattered with some picks having a large uncertainty (Figure 10A). Wind often made the environment noisy, making arrival times more difficult to pick. Many of the hammer points were rehammered in an attempt to acquire better data. The forward data may be fit better with five branches, including one delaying branch, resulting in a much more complicated travel time curve. However, this delay is primarily due to a sudden deepening of the third layer accompanied with some scatter. The reverse direction does not exhibit this same complication since the third layer has a large cross over distance of about 220 feet. The reversing first branch is quite scattered while the forward branch is more constrained. Due to the dramatic change in alluvial thickness the second branches are quite different in length, but both have comparable apparent velocities (forward is $6400 \mathrm{ft} / \mathrm{sec}$, reverse is $6500 \mathrm{ft} / \mathrm{sec}$ ). The third branches are also very different in length,as well as apparent velocity. Keeping the travel time curve simple, the forward data from 90 to 300 feet was averaged by the third branch with an apparent velocity of $9800 \mathrm{ft} / \mathrm{sec}$ (Figure 10A). Due to a steep upward dip in the reverse direction at the second interface, a very fast apparent velocity $(38000 \mathrm{ft} / \mathrm{sec})$ is measured for the third branch. Forward and reverse cross over points for the third branch occur around the same proximity on the line, about 80 feet on figure 10A. The three layer model tries to incorporate the above considerations, yet remain fairly simple (Figure 10B). A water table velocity is not recognizable in this model, however the water table may still exist within the imaged depth. The first layer is the usual sand and gravel down to about 9 to 10 feet. Somewhat consolidated fluvial clay, sand and gravel,with some boulders may make up the second layer with an average velocity of $6450 \mathrm{ft} / \mathrm{sec}$. Some water may also occur in this layer. The third layer is the lower Paleozoic to upper pre-Cambrian sedimentary rock exposed on the surface. However, the actual geometry of this interface can only be inferred with these data. This interface should suddenly steepen as the line obliquly leaves the outcrop (Figure 10B). Although water may occur in the fractures of the bedrock, water table is not expected to be encountered by the 130 foot drill hole, which should be in the bedrock within the first 10 feet.

\section{Shot Point 53}

About 2.2 miles south of Titus Canyon road off of the highway leading to Scotty's Castle is shot point 53 (Figure AI-13). The stake, at an approximate elevation of 115 feet, is located in a minor wash 240 feet south of the highway at the edge of an alluvial fan. The refraction line trends N65E along an abandoned dirt road, beginning at the southwest edge of the wash about 100 feet south of the stake (Figure AI-14). The road surface is very smooth with a small drop in elevation (about 3 feet) along the line. Towards the southwestern end of the line are some "evaporite mounds" buried just below the road surface with some outcrops in the area. These mounds are probably responsible for thinning the surface layer at this end (Figure 11B).

The travel time curves fit the data reasonably well with a bit of scatter (Figure 11A). Scatter is especially bad from 210 to 330 feet on the forward line, which may be partly due to lateral changes in the surface layer by some evaporite mounds, as well as irregularity of the second interface. A number of secondary points were hammered to help define the second cross over points and to confine some of the scatter. Despite the scatter, the reciprocating picks agree well with only a small difference of 1 msec. This model is similar to that of SP-35 where possible lake sediments occurr below the fan alluvium (Figure 11B). Sand and gravel make up the surface layer only 5 feet thick on the northeast end and probably less than a foot on the southwest end. As mentioned above, some crusty evaporite mounds possibly thin the upper layer. Layer two is probably a more consolidated fan material with an average velocity of about $2900 \mathrm{ft} / \mathrm{sec}$. Below 23 to $31 \mathrm{feet}$ is the third layer with an average velocity of about $6700 \mathrm{ft} / \mathrm{sec}$. The third layer likely consists of lake sands, clays, and evaporites, or possibly more fan material with a clay matrix. If the water table does not coincide with this layer then it likely occurs below about 80 feet. Although, the water table has no recognizable velocity in this survey, the 130 foot drill hole is expected to penetrate it. 


\section{Shot Point 54}

Shot point 54 is located 0.8 miles south of the highway leading to Scotty's Castle, on the Mesquite Spring Campground road, about 1 mile north of the campground (Figure AI-15). The survey line begins about 50 feet east of the road, and trends upslope along the wash at N43E (Figure AI-16). Mesquite Spring is located about 1 mile south at an elevation of about 1770 feet. Located near the head of an alluvial fan, the site has an approximate elevation of 1980 feet. The geophones were placed in the largest clearing possible to avoid noise from bushes being rustled by the wind. However, at the beginning of the survey the wind made the distant reversed arrivals difficult to pick, resulting in large uncertanties (Figure 12A).

The data have very little scatter and the travel time curves are easily fit (Figure 12A). However as mentioned above, the reversed picks made at the beginning of the survey have a large uncertainty due to the wind. As the sun set over the Panamint Range the wind died down and the environment became very quiet. The forward fourth branch is constrained very well with a reciprocal pick at 111.8 msec. Due to the large uncertainties the reversed fourth branch is only inferred resulting in an unreversed fourth layer. Although four layers were defined, no water table is recognized (Figure 12B). The layers parallel the surface with very little dip. Wash sand and gravels make up the surface layer with an average velocity of about $1200 \mathrm{ft} / \mathrm{sec}$. Increased compaction with depth give the first layer a seismic thickness of 3 feet to the southwest and 4 feet to the northeast. Compared to the first layers, the second layer probably consists of a more consolidated fan and wash material with an average velocity of $2200 \mathrm{ft} / \mathrm{sec}$. The third layer may be a yet more consolidated continuation of horizons one and two, with the interfaces between them existing only seismically instead of a contact that can be recognized in drilling. However, this third layer could also be stratigraphically different than the second, such as a higher sand content allowing for a sudden increase in compaction and velocity. The fourth layer is only defined by the forward apparent velocity (8300) since a reliable reversed velocity was not obtained. An interface parallel to the surface is inferred at 74 feet depth with no resolved dip (Figure 12B). The fourth layer could be mostly clay with some sand and gravel, or possibly a fanglomerate, which could contain water. The water table is at least 74 feet deep and probably is much deeper than the proposed 130 foot drill hole. 


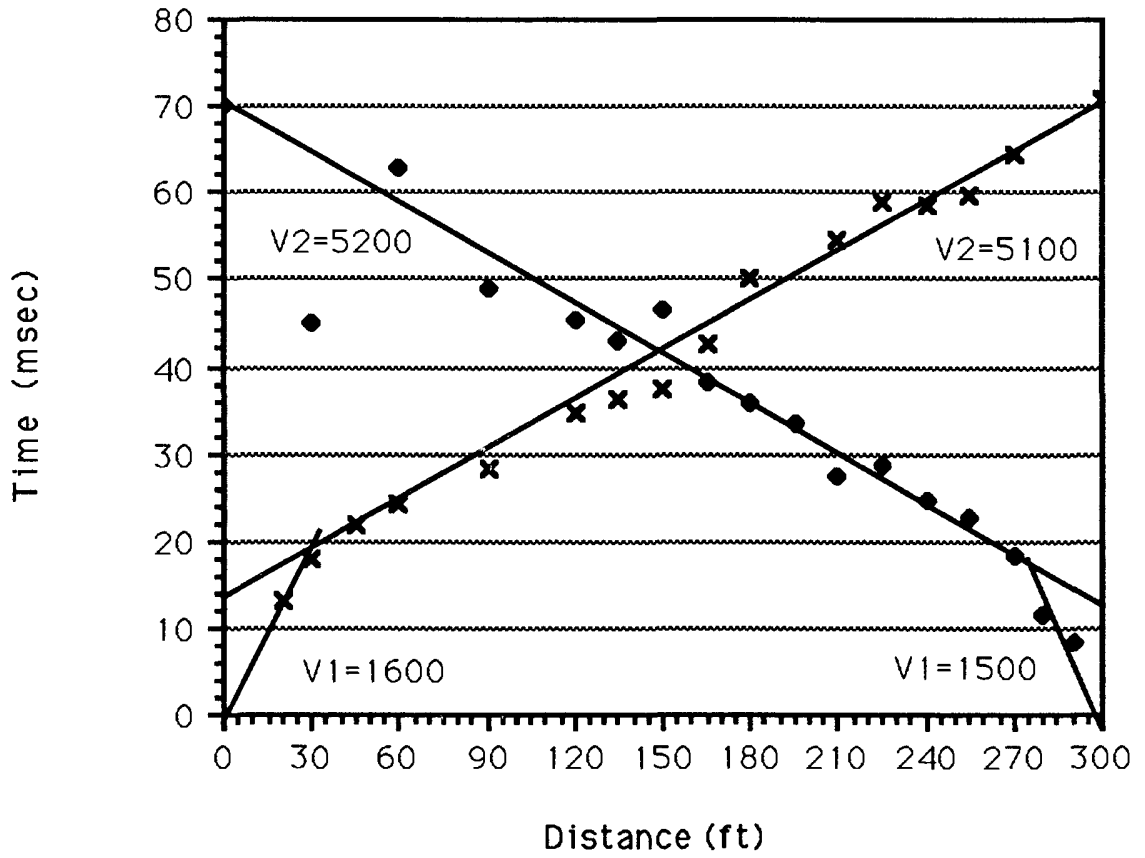

* Forward

- Reverse

B

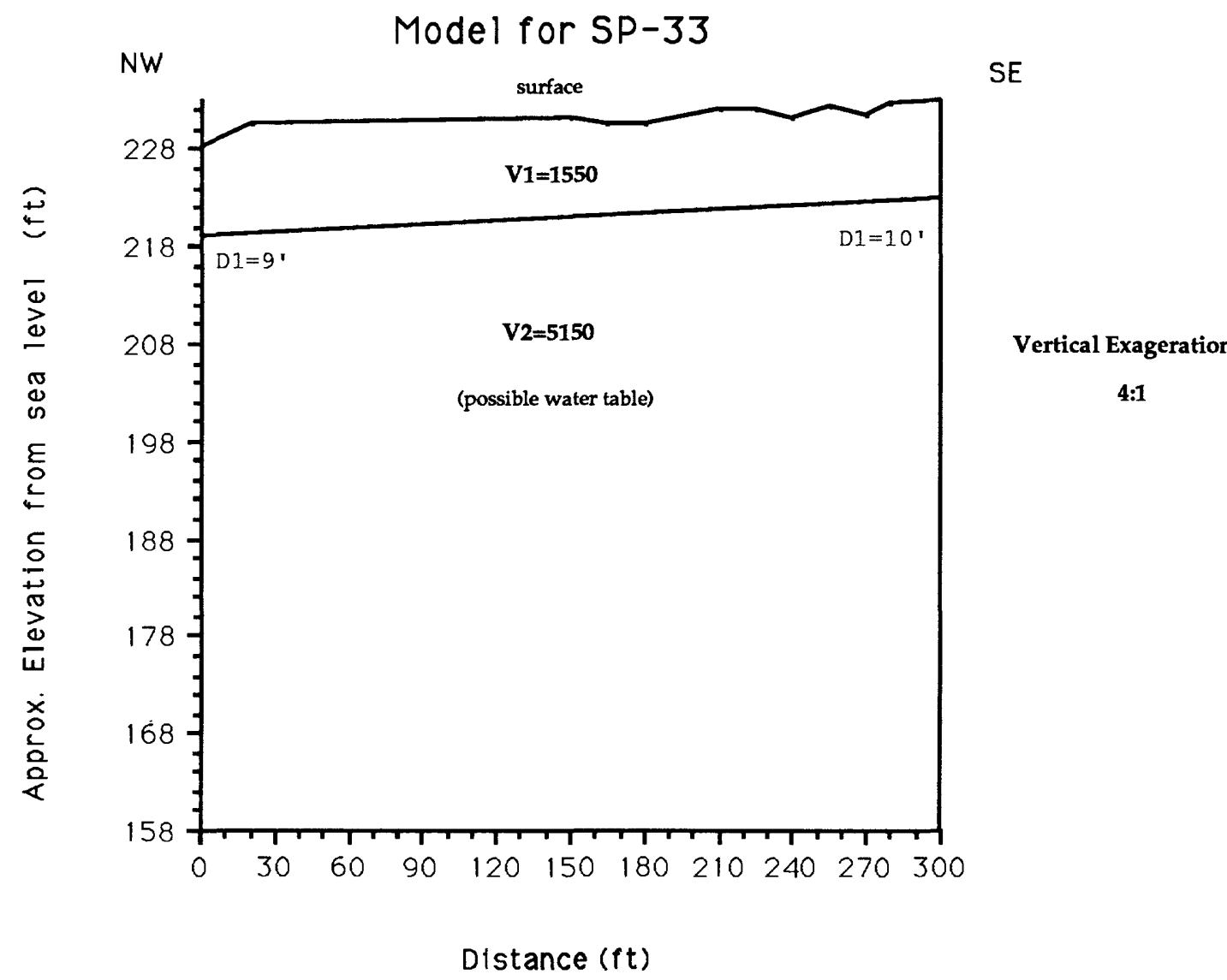

Figure 5. A: Travel time curves for SP-33. Although the end of the reversed data is very scattered, the reciprical picks agree very well. B: Two layer model derived from the travel time curves. The second layer is somewhat fast, and shallow for the water table, however it may contain some water. 
A

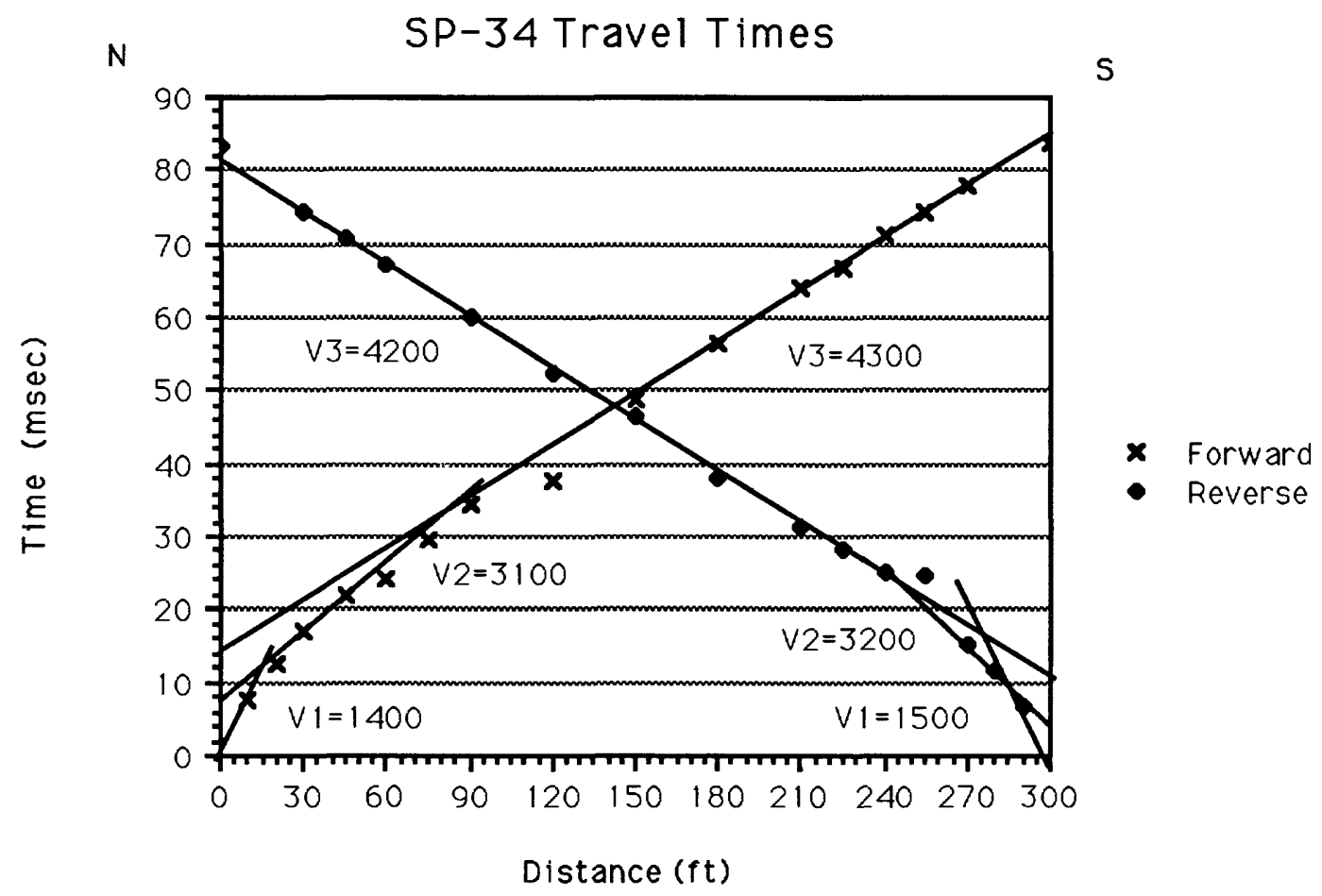

B

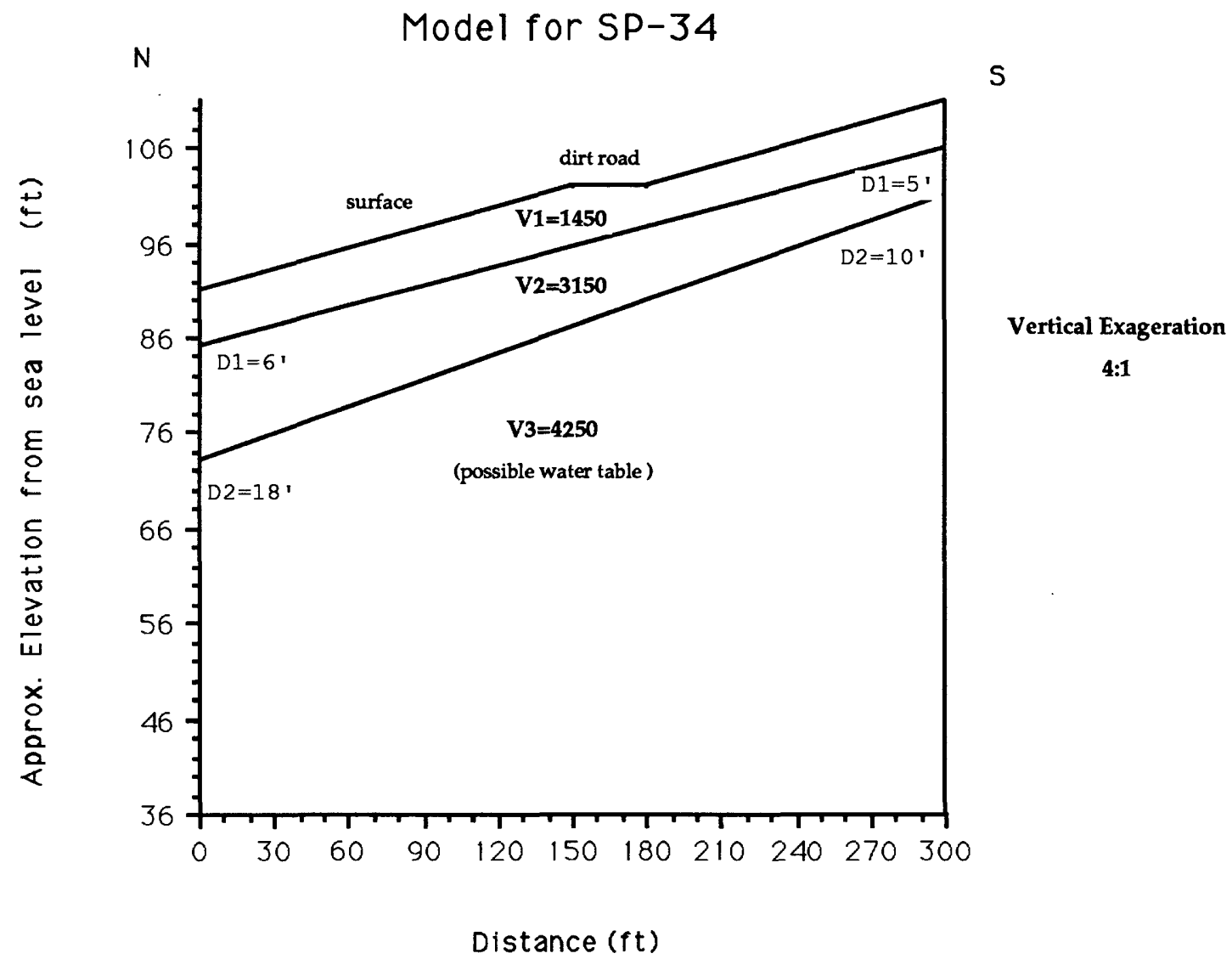

Figure 6. A: Travel time curves for SP-34. B: Three layer model derived from the travel time curves. The third layer probably contains water, however, its probably not the water table. 
A

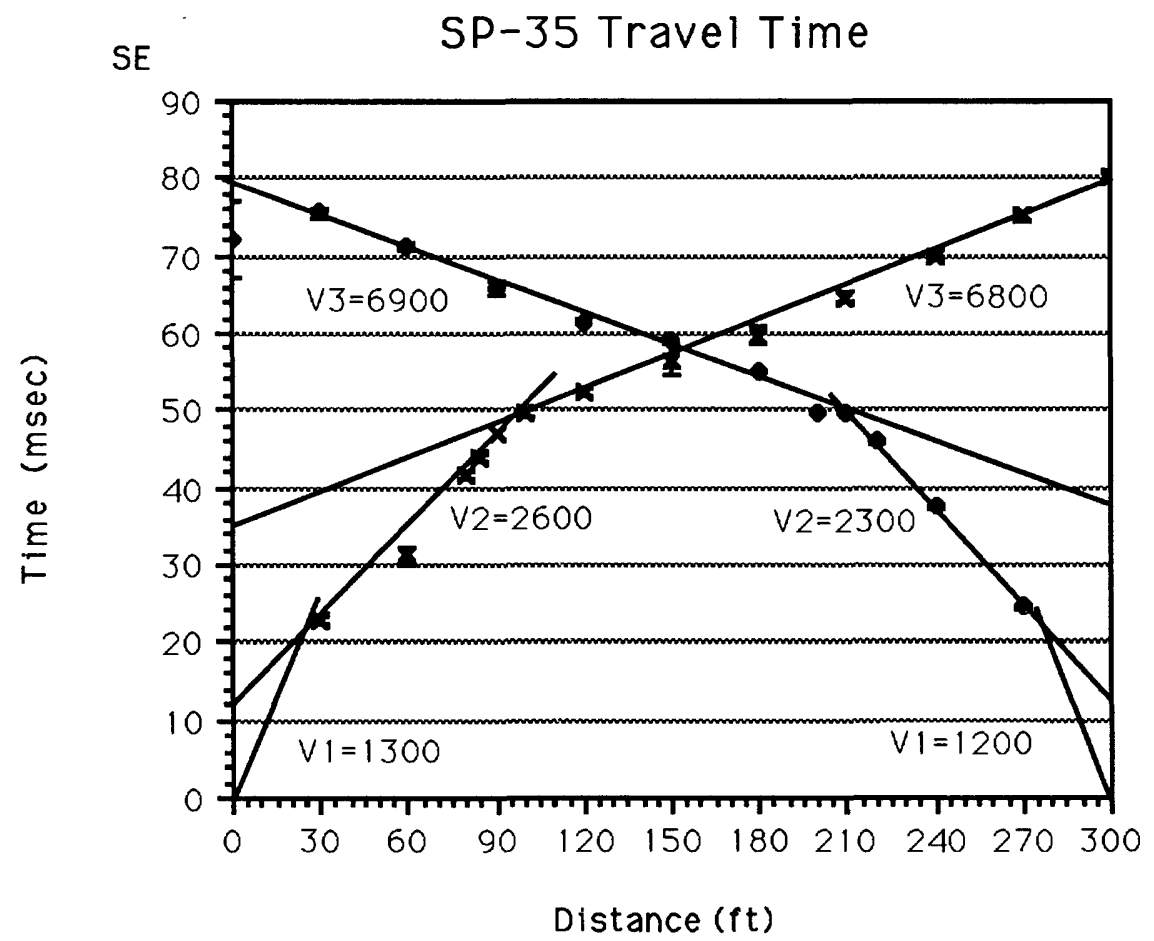

NW

x Forward

- Reverse

B

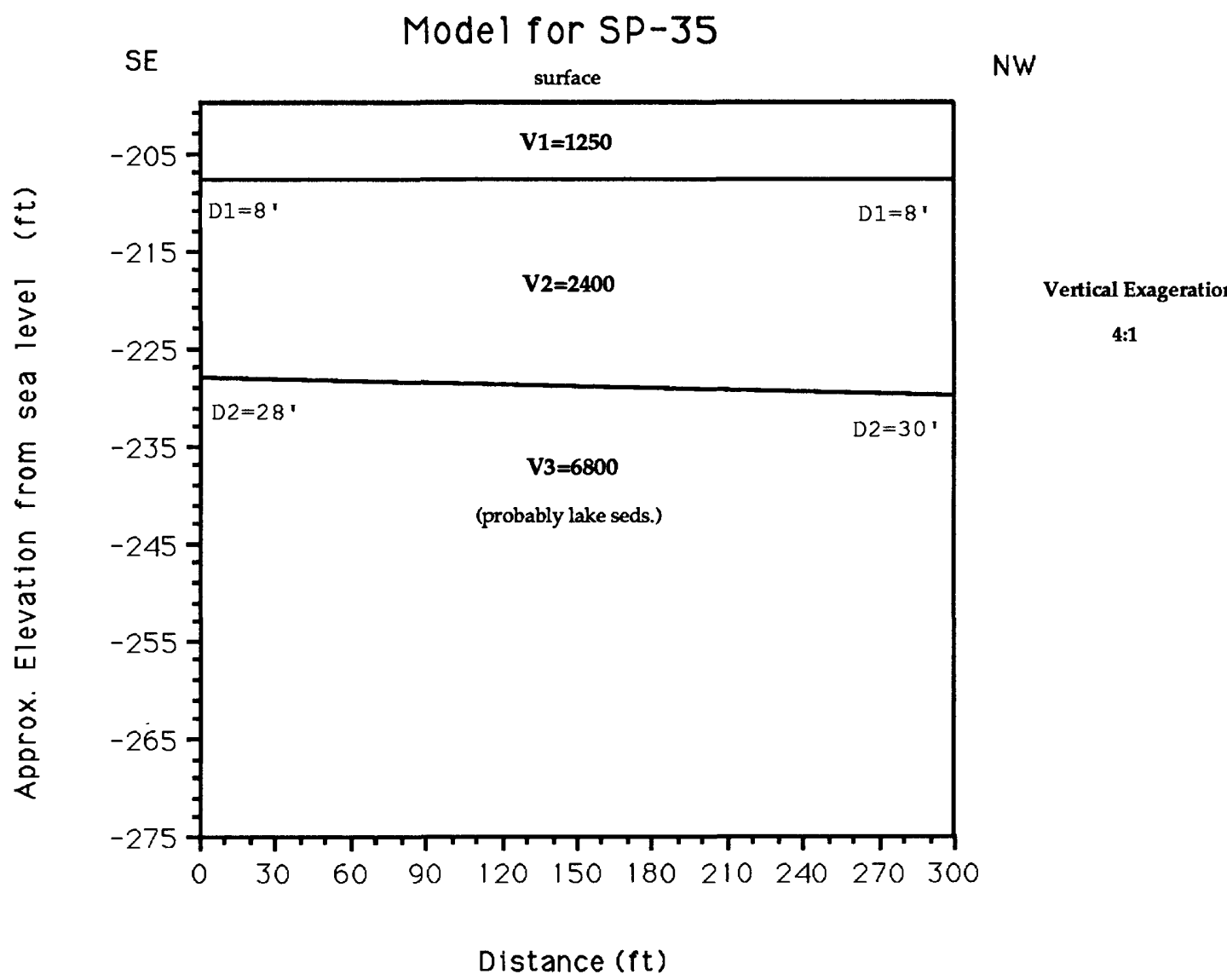

Figure 7. A: Travel time curves for SP-35. Although no picks were made for the first layer, its interpolation agrees well with the average. B: Three layer model derived from the travel time curves. Although the water table is hidden by the fast third layer, it is expected to be encountered by the 130 foot drill holes. 
A

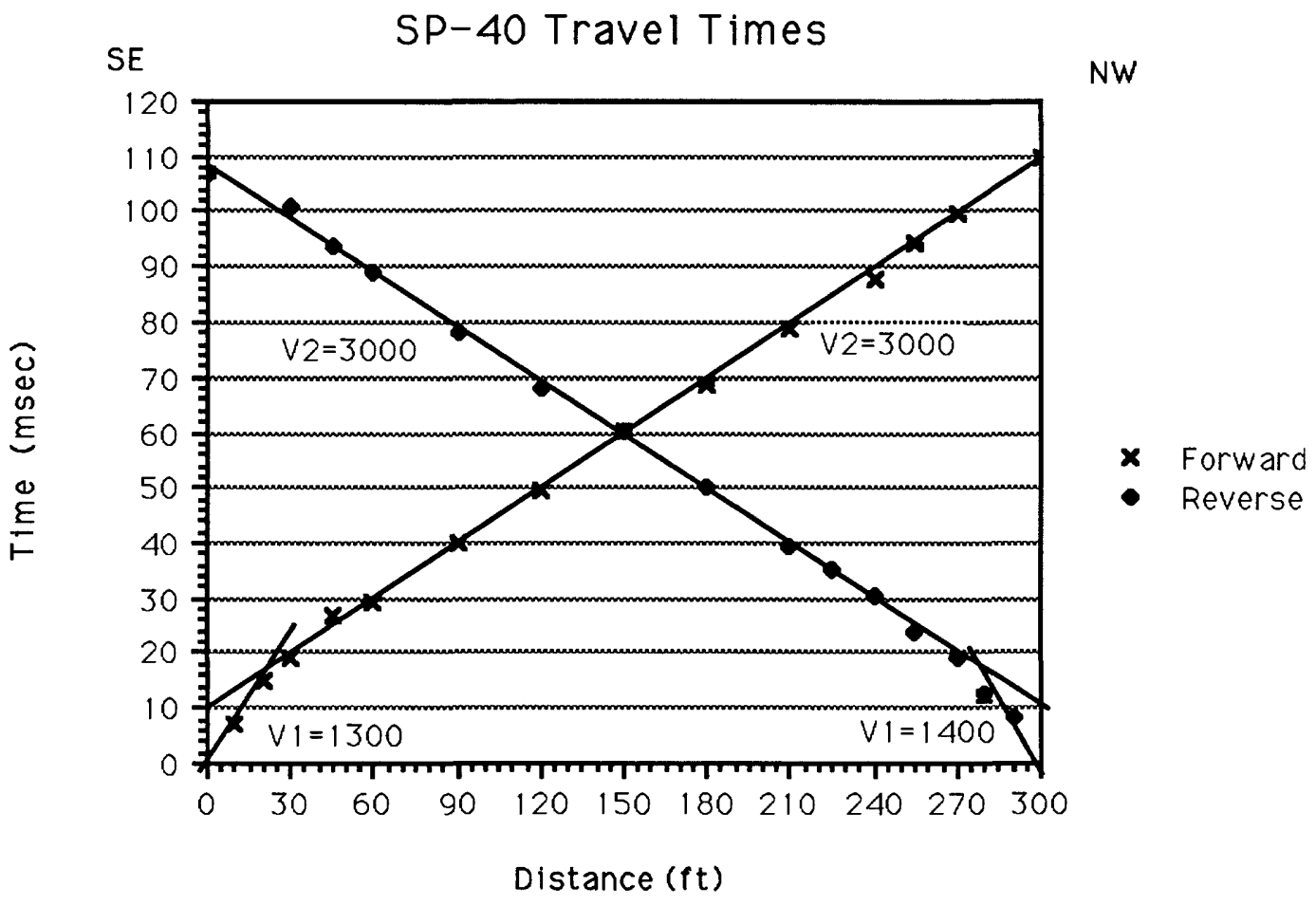

B

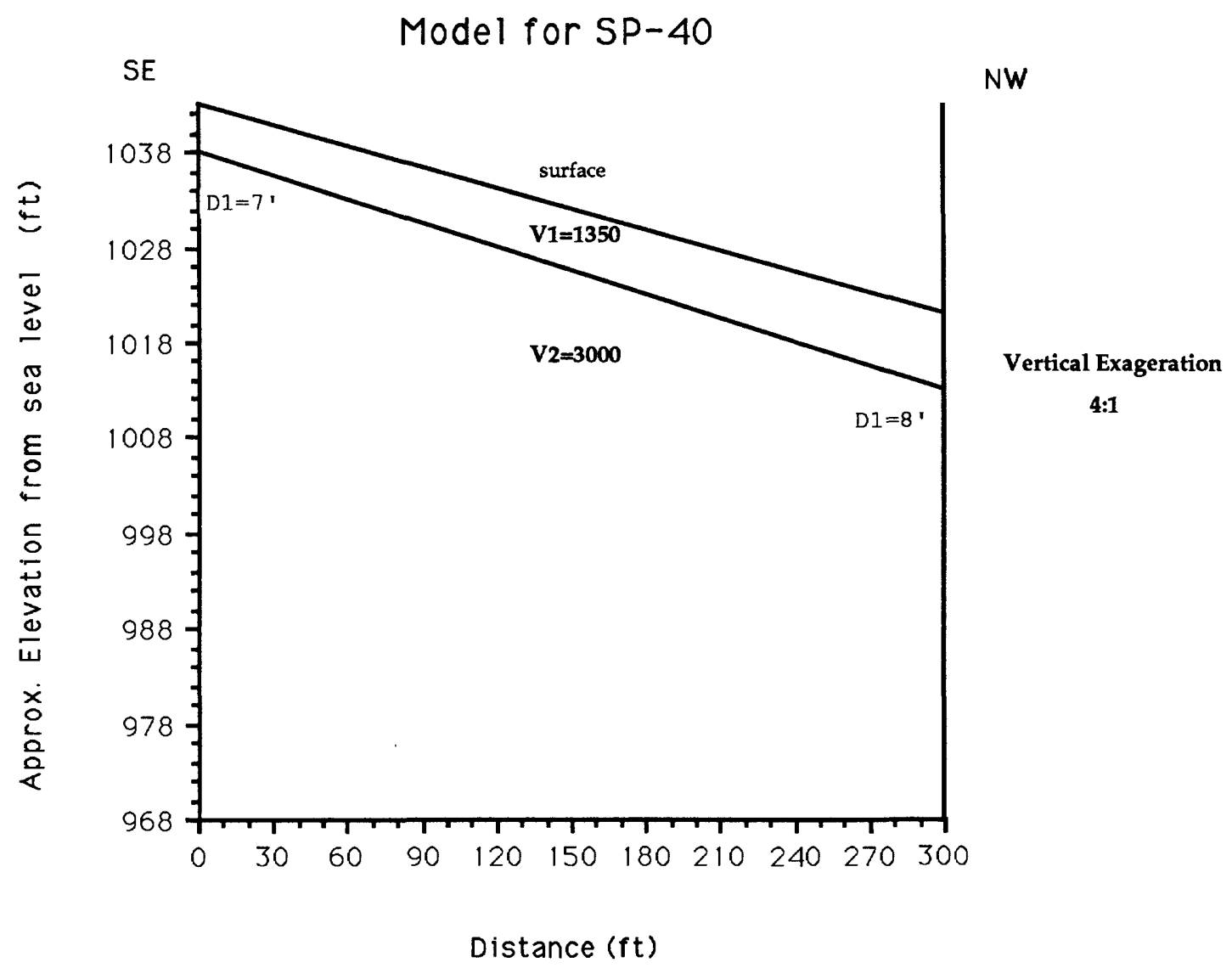

Figure 8. A: Travel time curves for SP-40, constrained exceptionally well for this area. B: Two layer model derived from the travel time curves. The water table is at least 80 feet, and probabbelow the proposed 130 foot drill hole. 
A

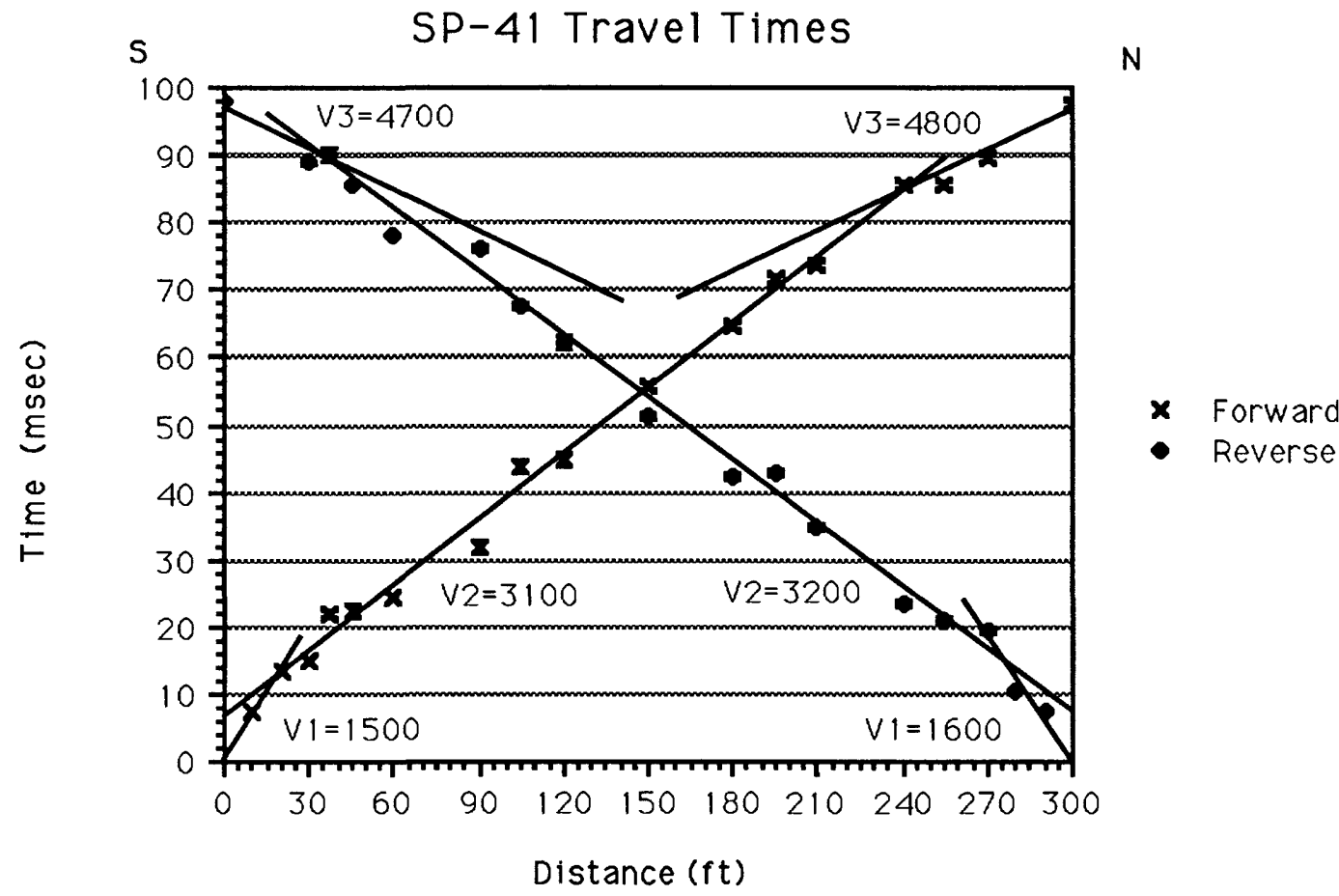

B

S

Model for SP-41

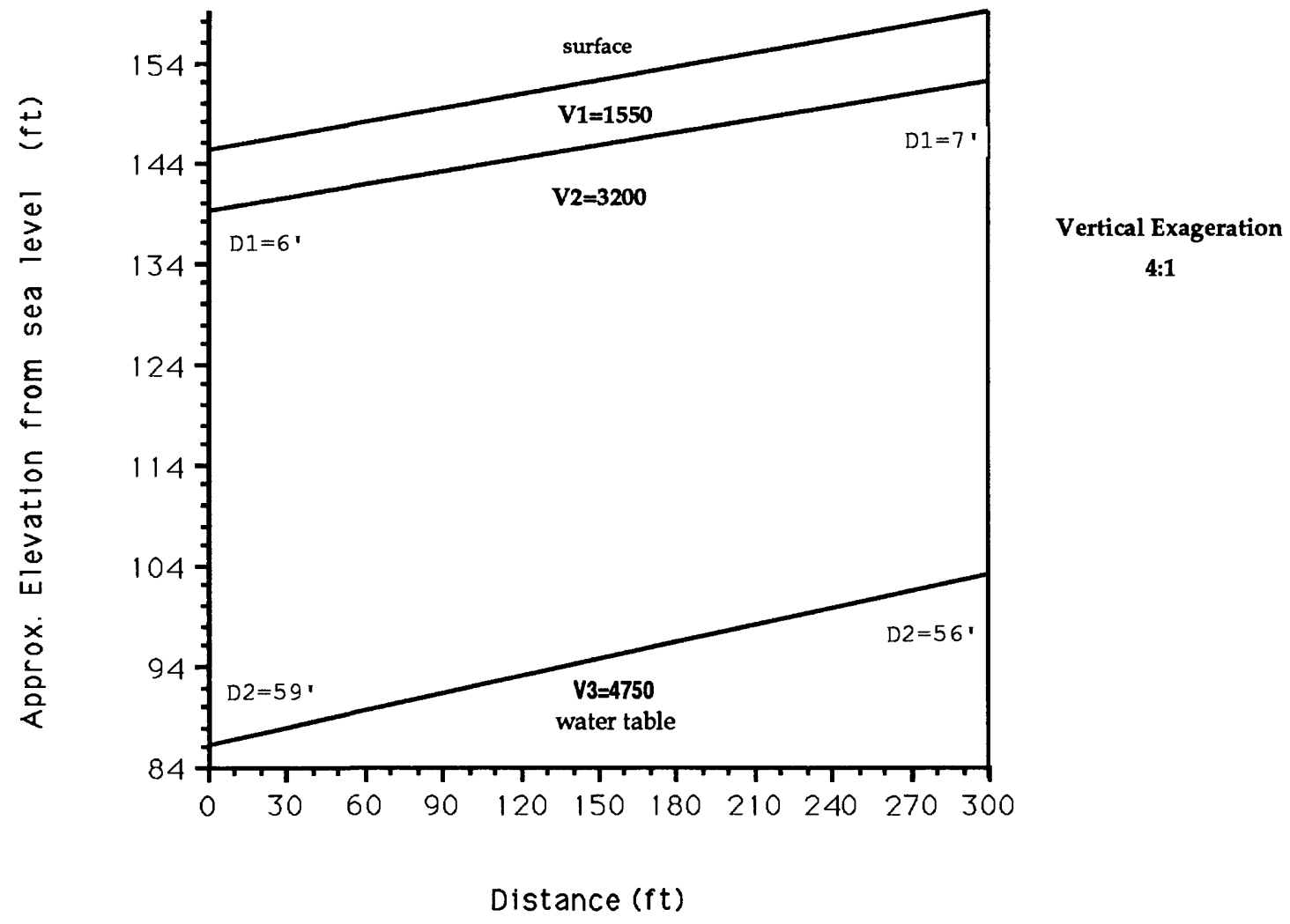

Figure 9. A: Travel time curves for SP-41. B: Three layer model derived from the travel time curves. The third layer is believed to be the water table. 
A

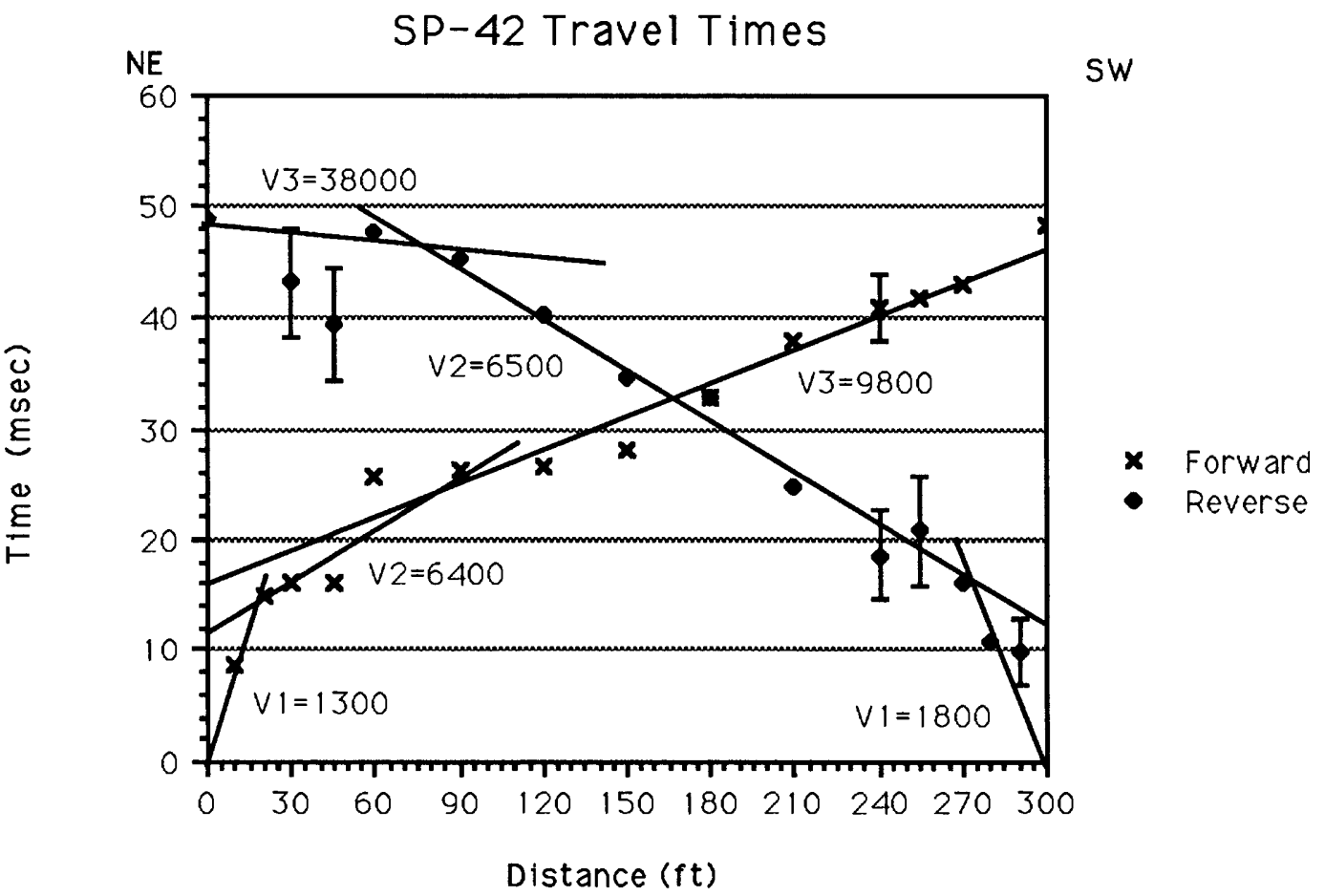

B

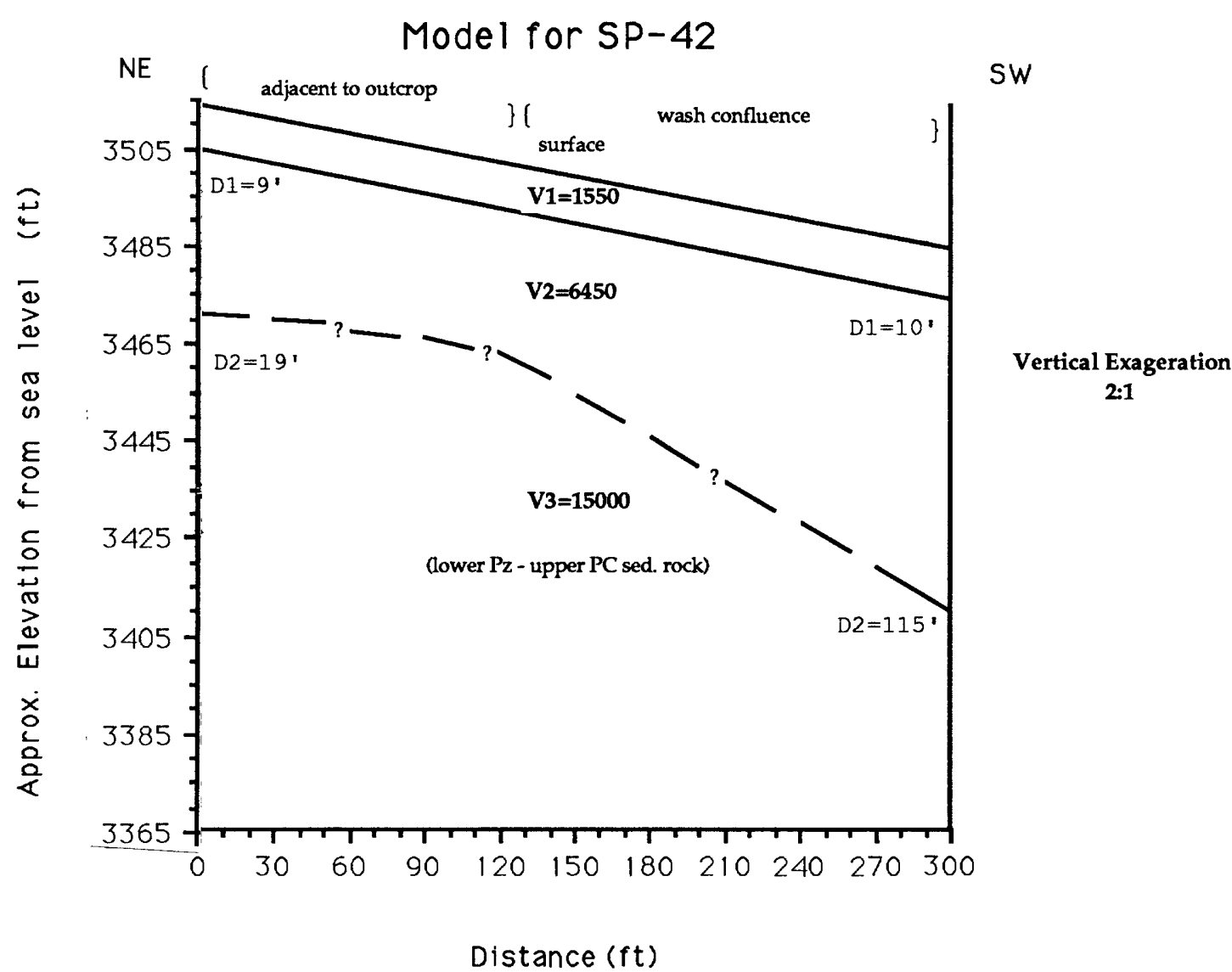

Figure 10. A: Averaged travel time curves for SP-42. B: Three layer model derived from the travel time curves. The top of the third layer is only inferred due to the poor constraint by the data. The third layer deepens as the line moves away from the outcrop and into the wash confluence. The 130 foot drill hole should be in the bedrock within the first 10 feet and is not expected to reach the water table. 
A

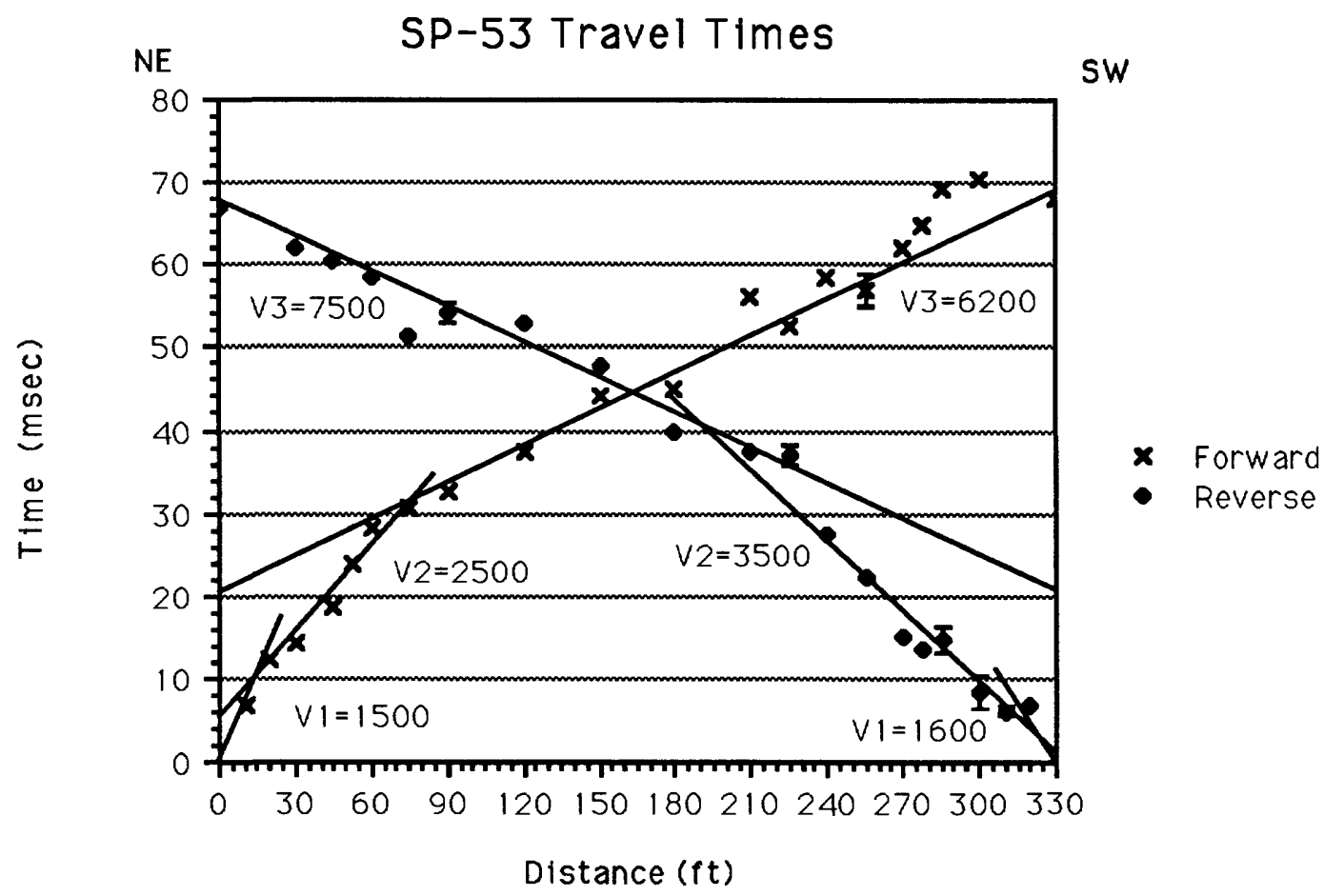

$\mathrm{B}$

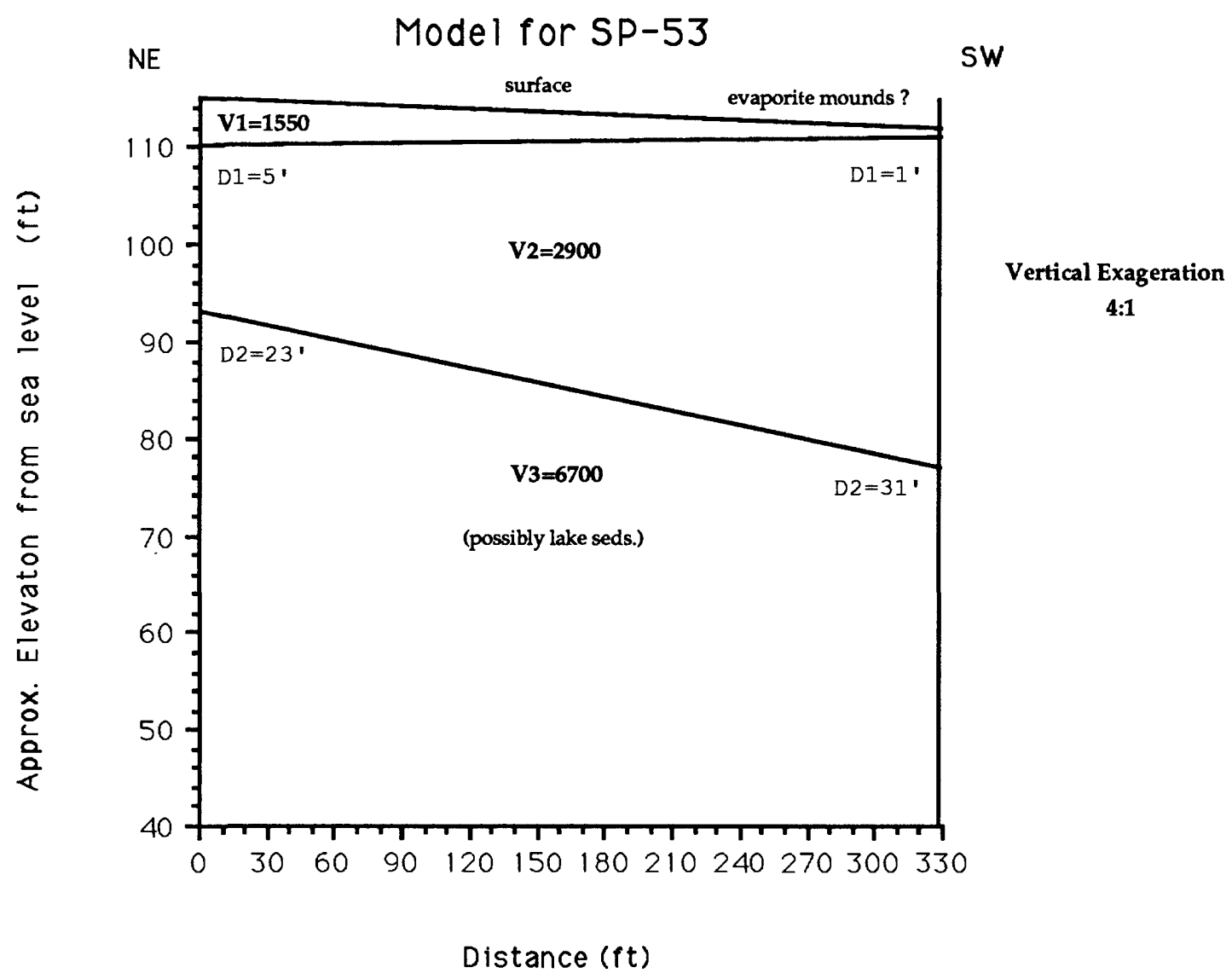

Figure 11. A: Travel time curves for SP-53. B: Three layer model derived from the travel time curves. Thinning of the first layer is probably due to some evaporite features that outcrop on either side of the line near the SW end. Although the water table is hidden by the fast third layer, it is expected to be penetrated by the 130 foot drill hole. 


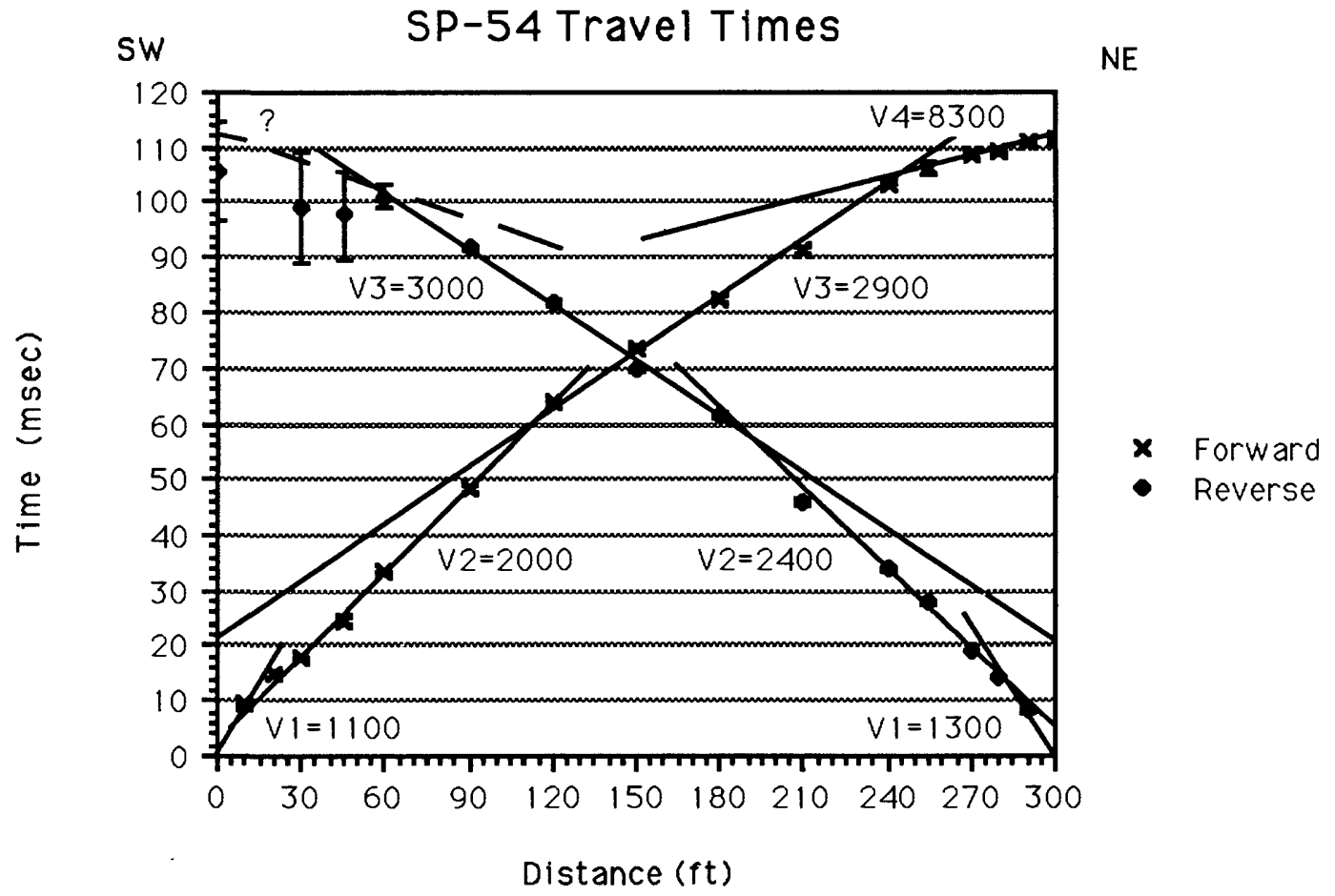

$\mathrm{B}$

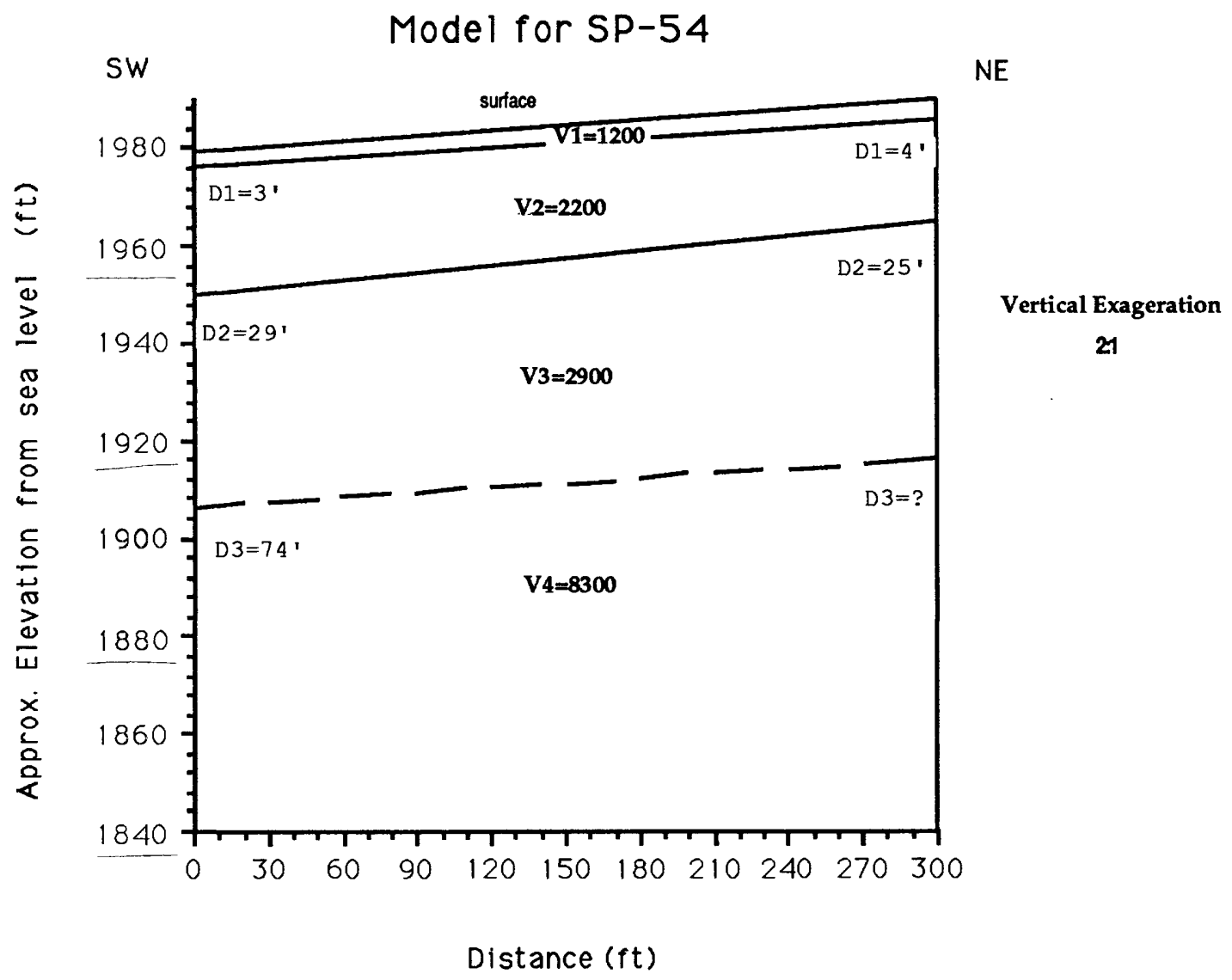

Figure 12. A: Travel time curves for SP-54. The reversed fourth branch is poorly constrained due to wind noise. B: Four layer model derived from the travel time curves. The fourth layer is inferred since it is essentially unreversed. The water table occurs at least below 74 feet and is not expected to be encountered by the 130 foot drill hole. Although the survey was performed at an alternate site, the results should be very similar to the proposed site 0.3 miles to the south. 


\section{ACKNOWLEDGEMENTS}

A big thanks to John Tinsley who loaned us most of the field equipment and was available when we encountered problems or needed advice. Joseph Cotton helped in the field by hammering or picking arrivals on half of the lines. Also thanks to Fred Fischer for his guidence with some of the Apple Macintosh software.

\section{REFERENCES}

Buono, A., and Packard, E. M., 1982, Evaluation of increases in dissolved solids in ground water, Stovepipe Wells Hotel, Death Valley National Monument, California: U. S. Geol. Surv. Open File Report USGS-OF-82-513, 19 pp.

Criley, E., Geist, E., 1987, Environmental Assessment for a Seismic Refraction Survey of Death Valley, an unpublished technical report of the U.S. Geol. Surv., 39 pp.

Cummings, D., 1979, Computer Program: Determination of depths to an irregular interface in shallow seismic refraction surveys using a pocket calculator, Geoph., v. 44, p. 1987-1998.

Duguid, J. O., Refraction determination of water table depth and alluvium thickness, Geoph., v. 33, p. 481-488. 


\section{Appendix I:}

\section{Shot Point Location Maps and Sketches}

Distances and elevations shown on the sketches (Figures AI-2, AI-4, AI-6, AI-8, AI-10, AI-12, AI-14, and AI-16) are not to scale. The shallow refraction lines are shown on the sketches (site plans) as a large arrow labeled with a compass bearing indicating the trend of the line. The direction of the arrow shows the arbitrary direction in which hammer points were labeled. 


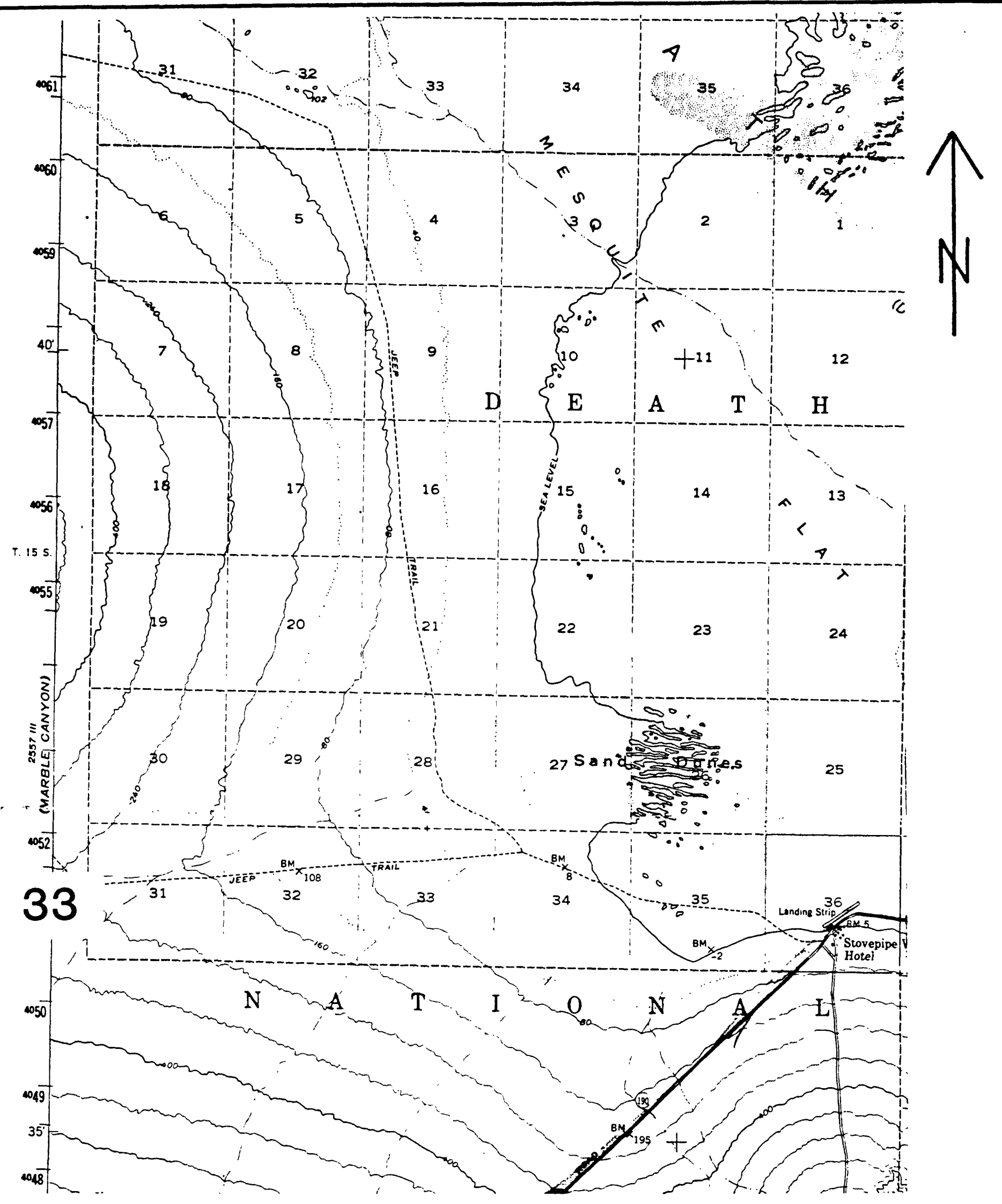

SHOT POINT 33

TOPOGRAPHY (USGS 15 min QUAD)
FIGURE

\section{AI-1}

(from Criley and Geist, 1987) 
$-19-$

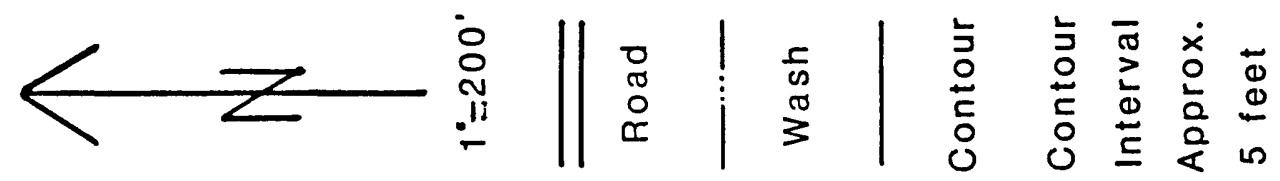

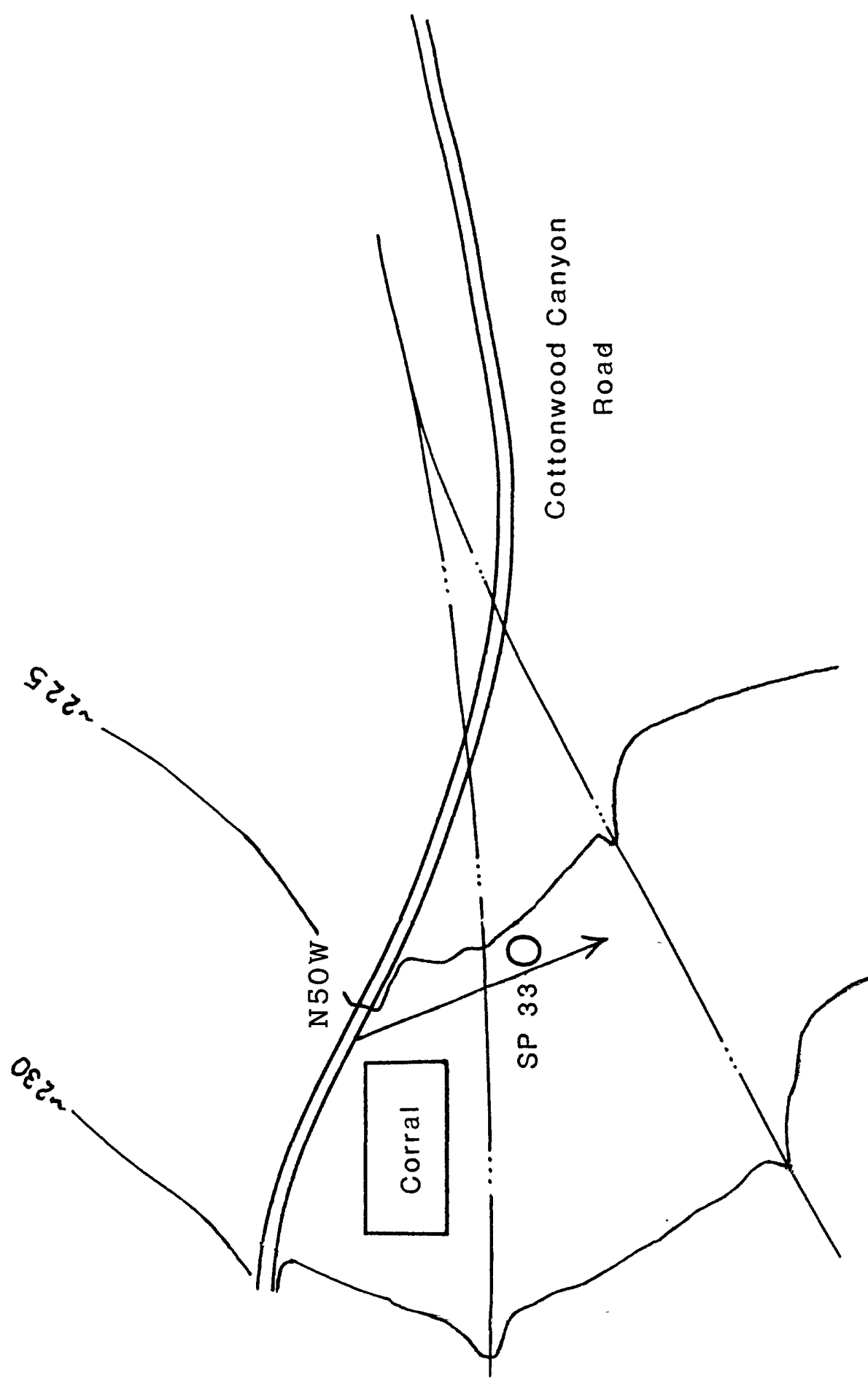

$m$

$\begin{array}{ll}m & Z \\ \frac{Z}{0} & \frac{1}{0} \\ 0 & \amalg \\ \frac{1}{0} & \frac{1}{\infty}\end{array}$ 


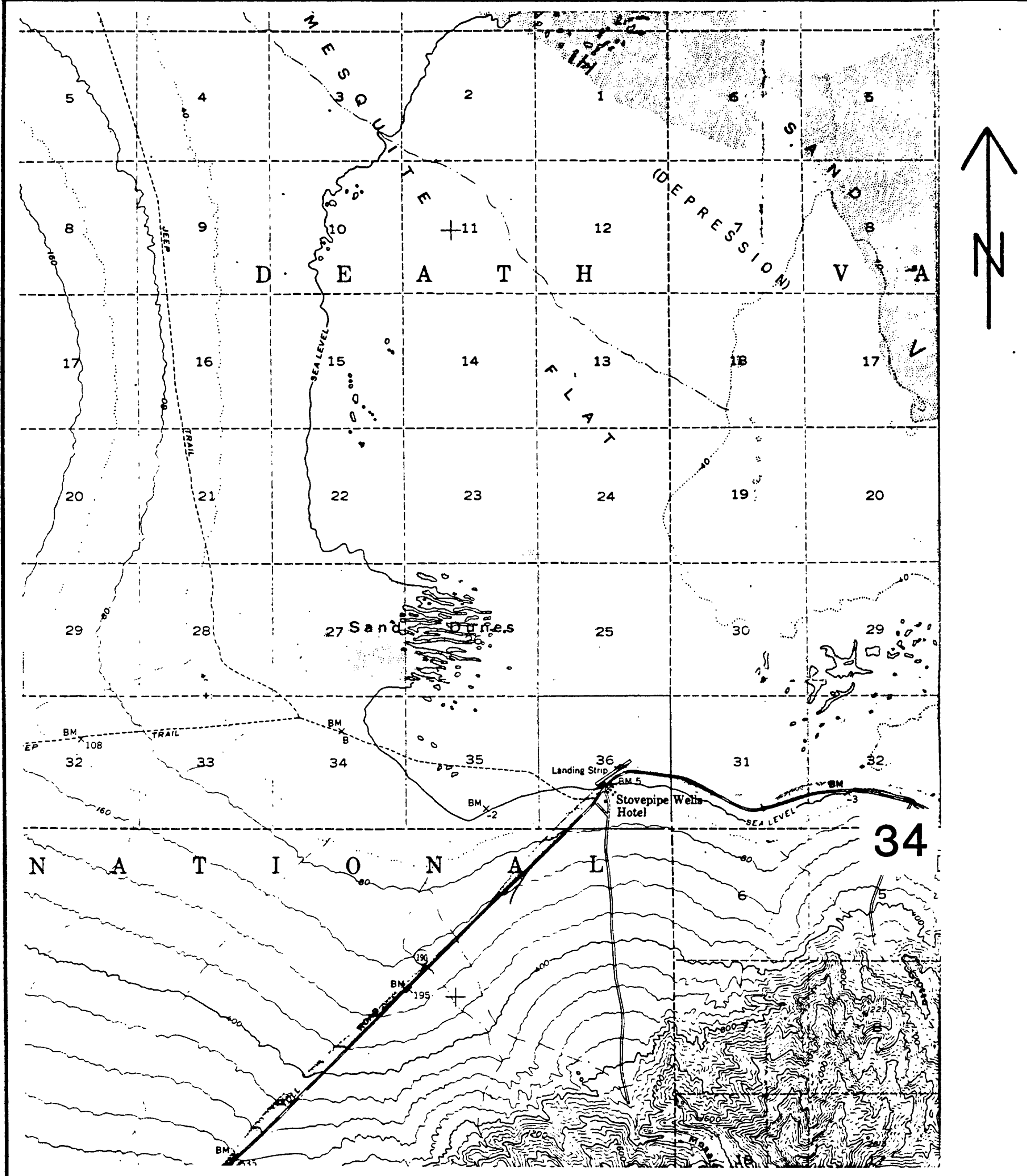

SHOT POINT 34

TOPOGRAPHY (USGS $15 \mathrm{~min}$ QUAD)

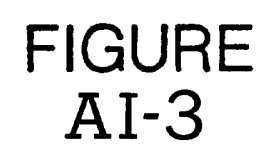

AI-3

(from Criley and Geist, 1987) 


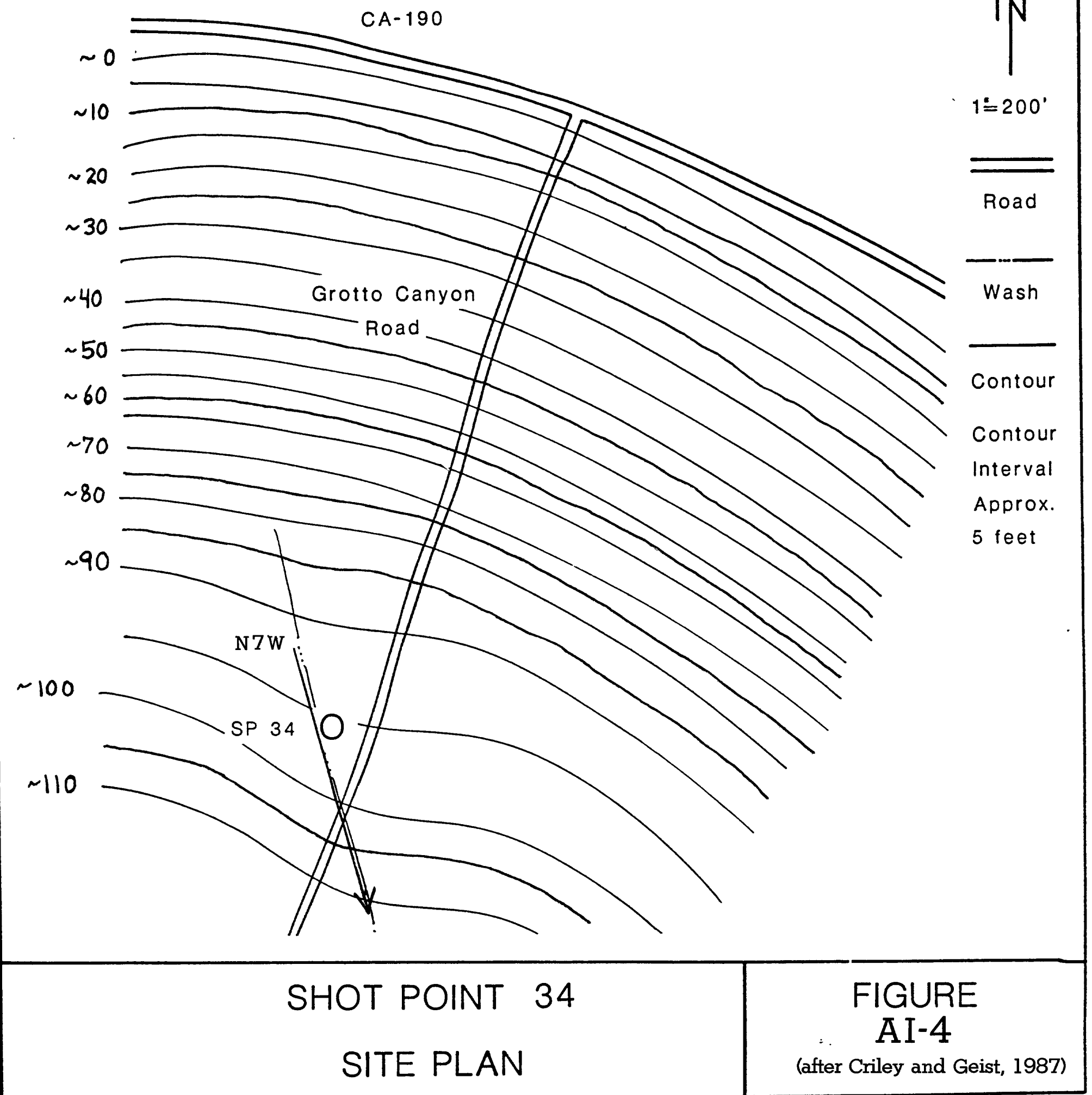




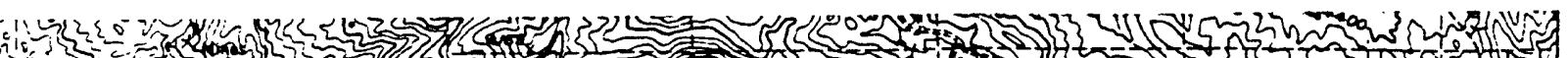
(1)

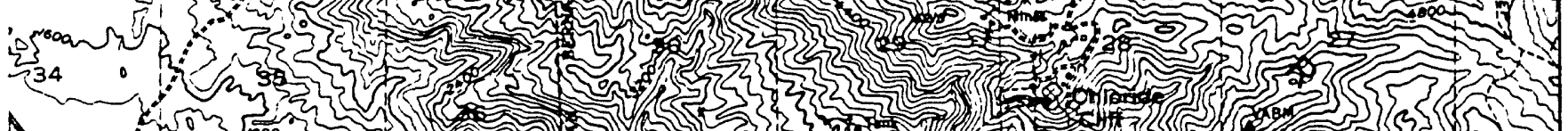

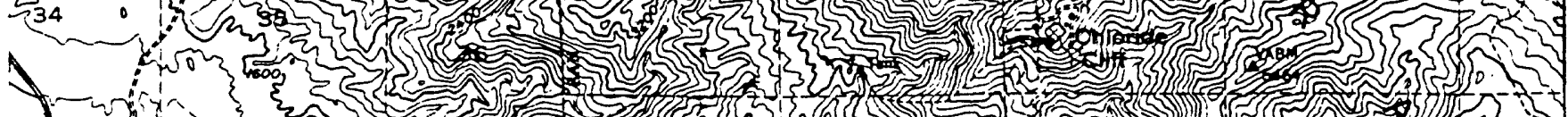

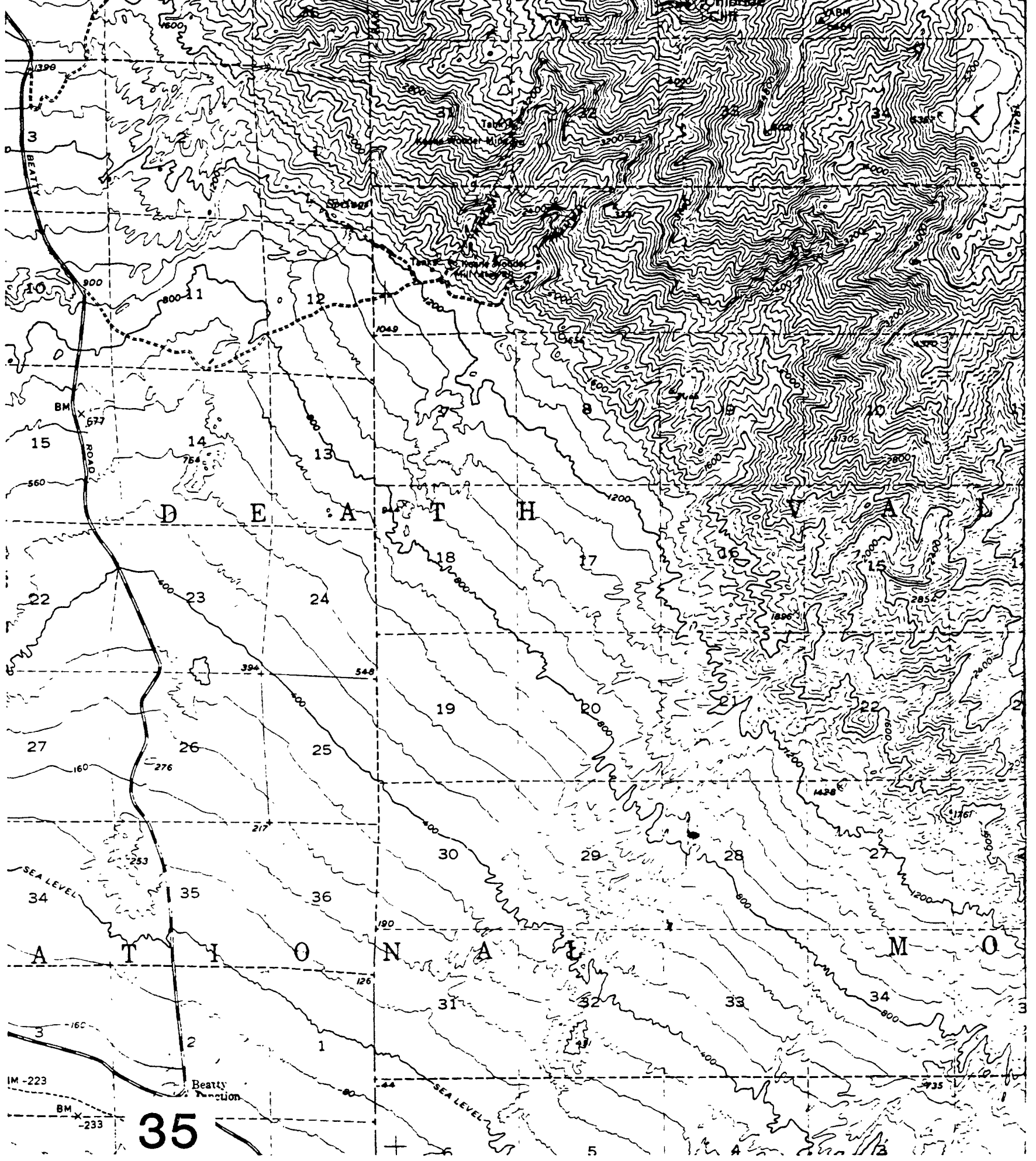




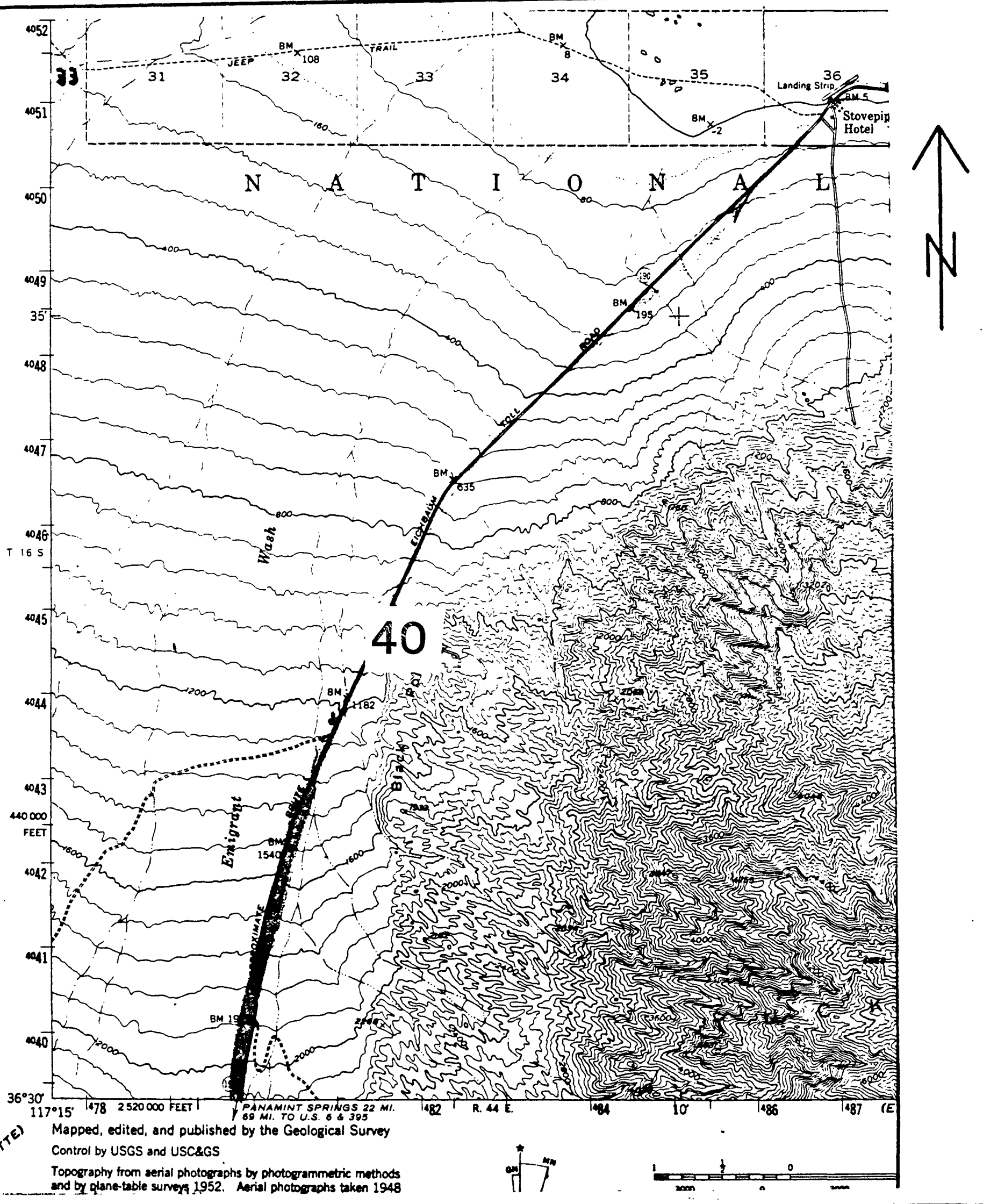

\section{SHOT POINT 40}




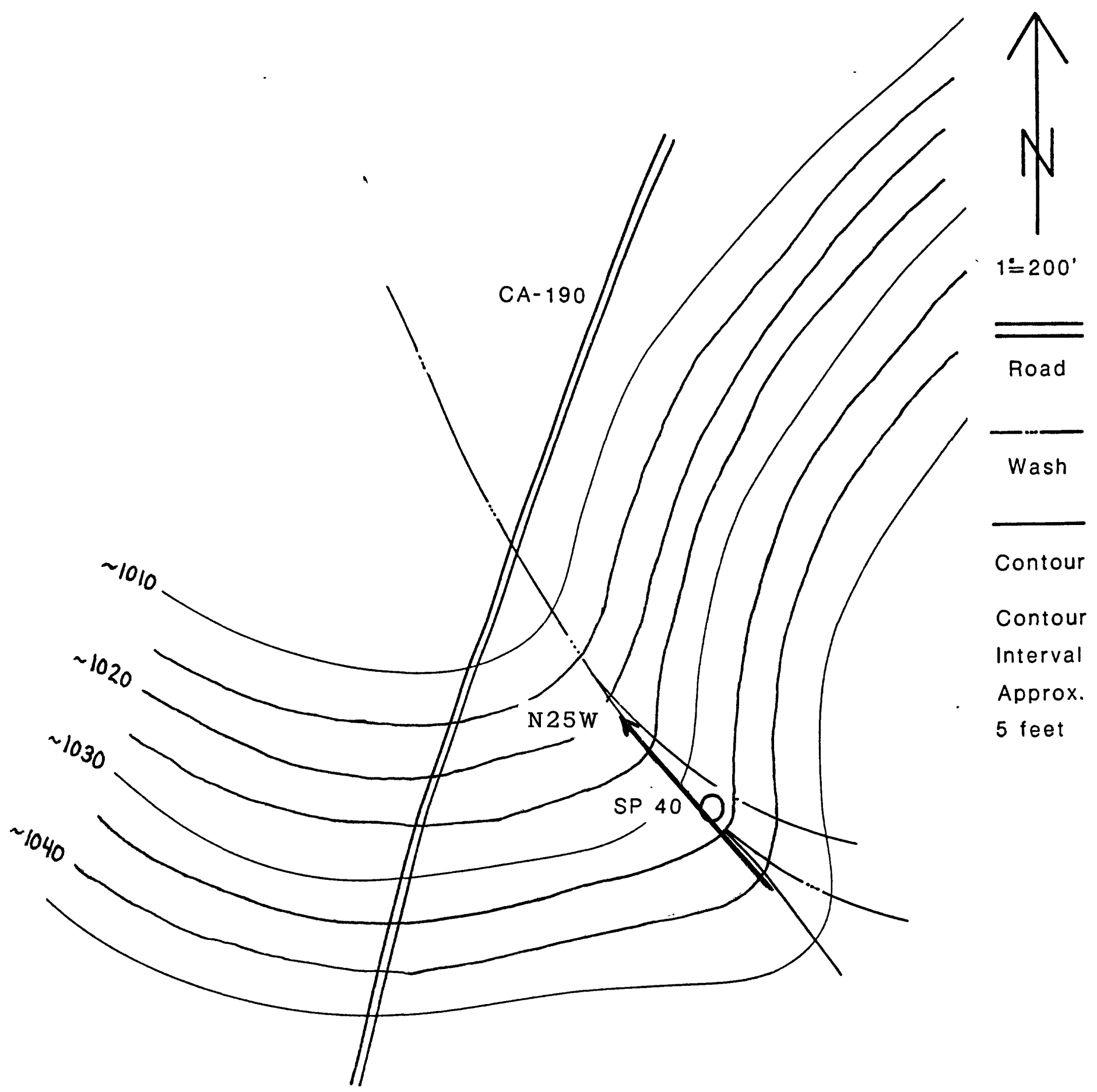

$\sim 1040$ 


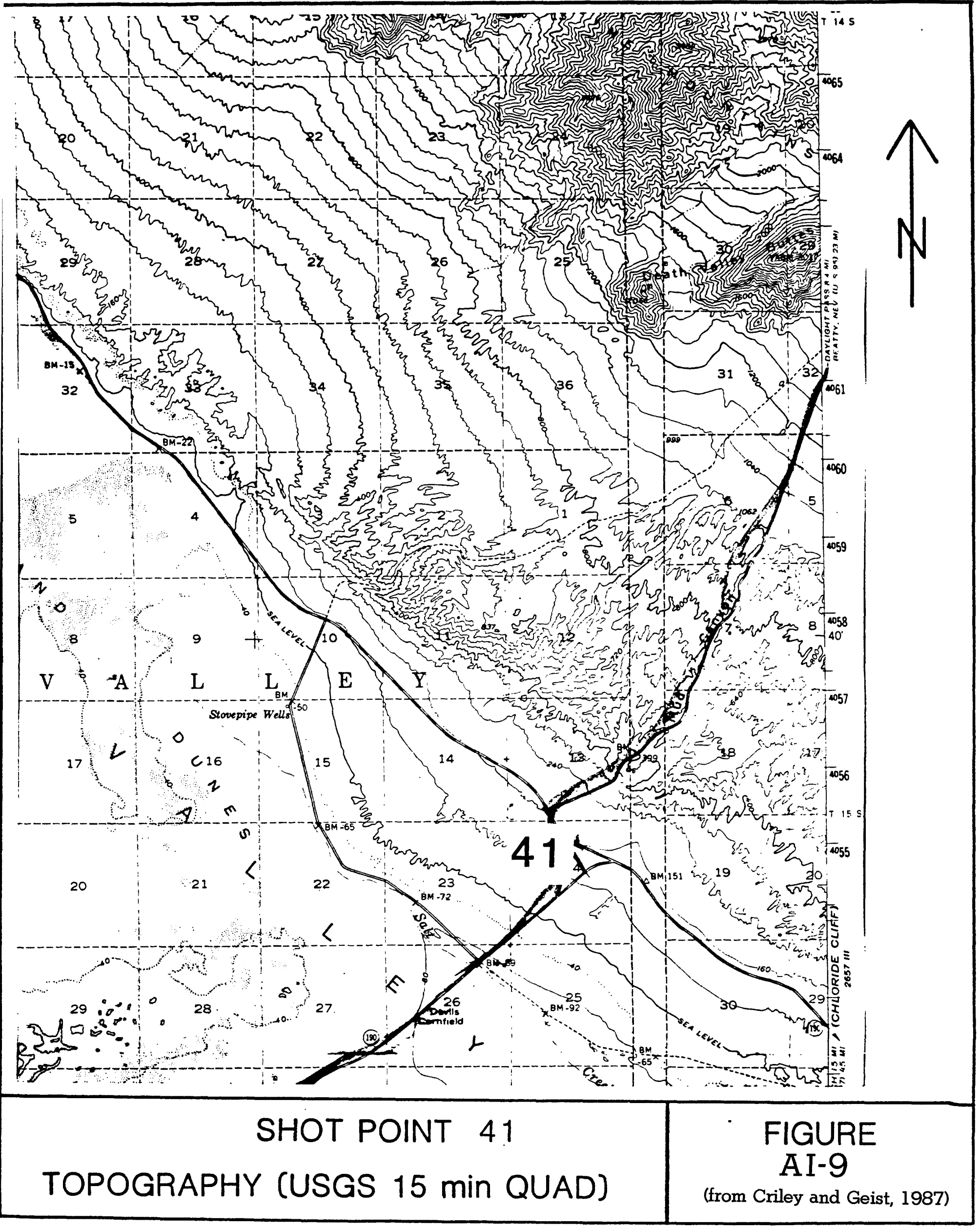




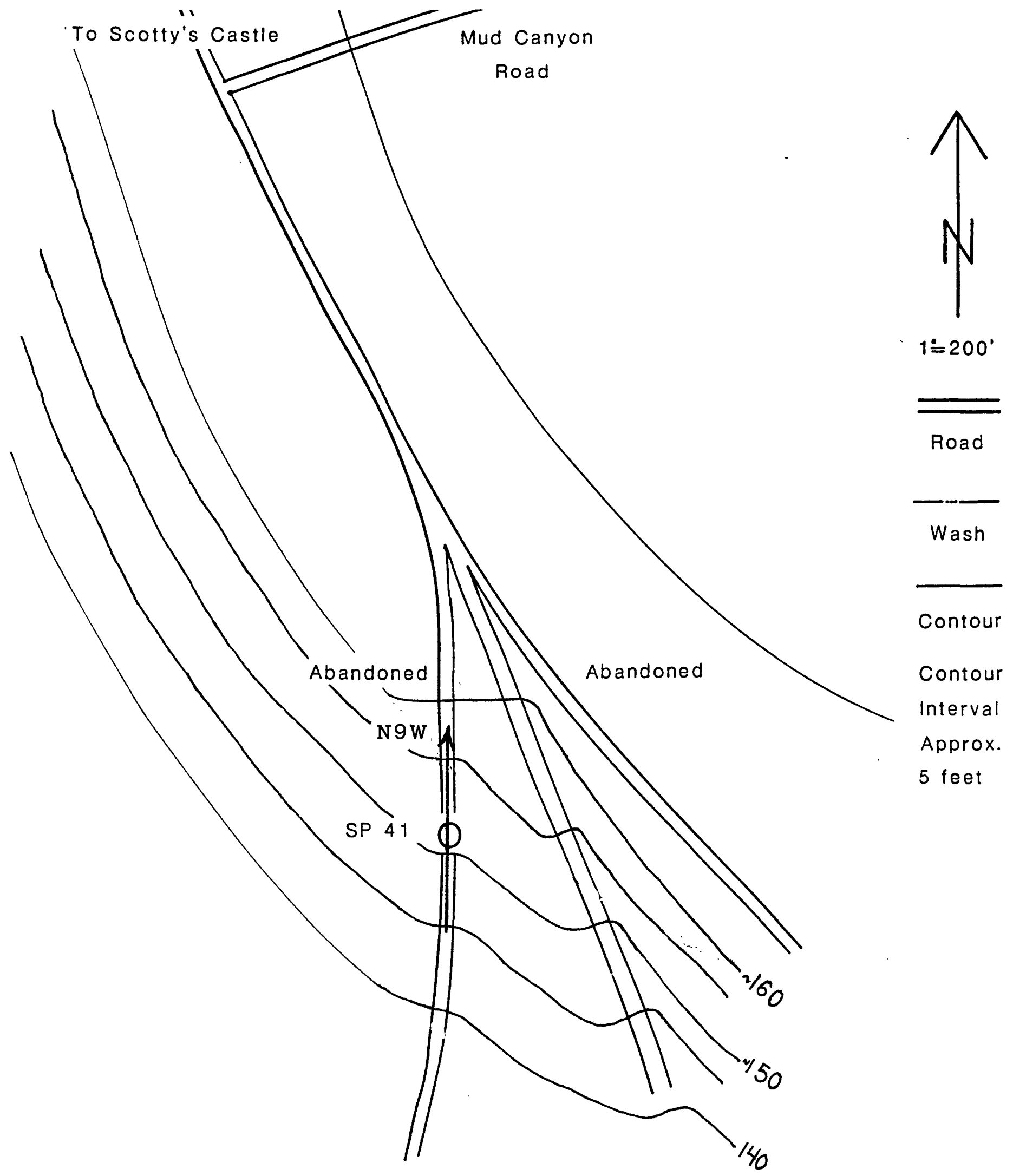

SHOT POINT 41 


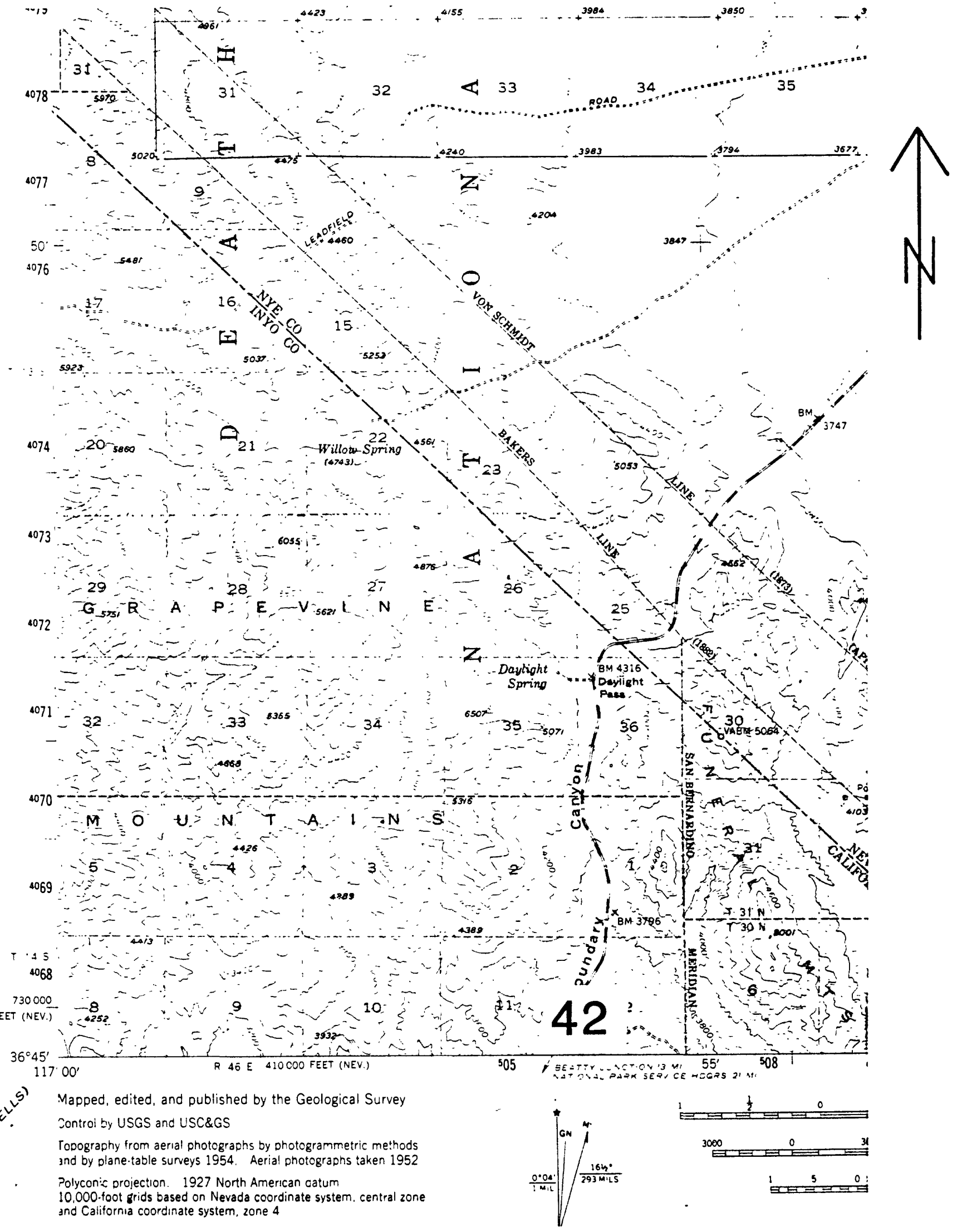

SHOT POINT 42

TOPOGRAPHY (USGS 15 min QUAD)

FIGURE

AI-1 1

(from Criley and Geist, 1987) 


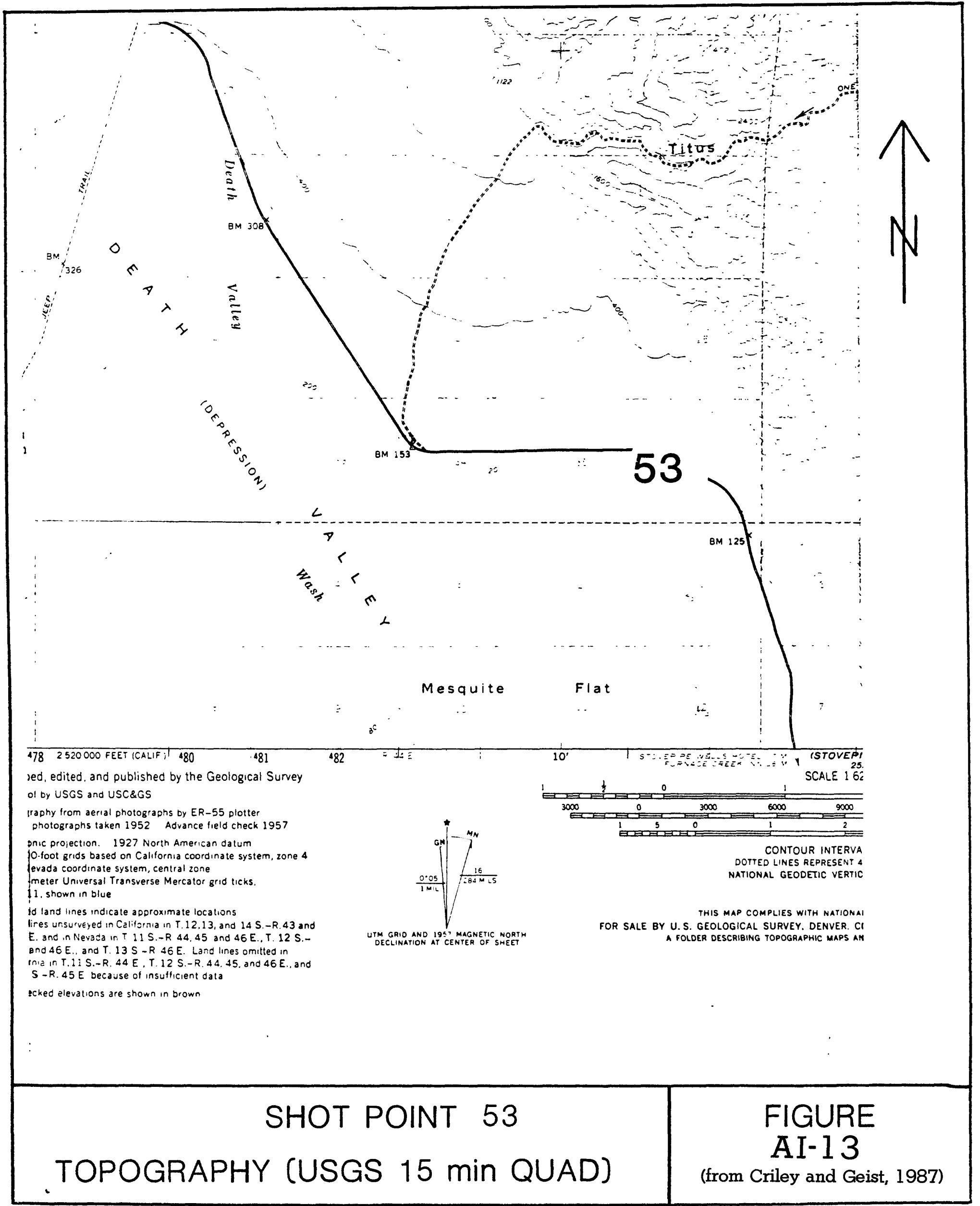




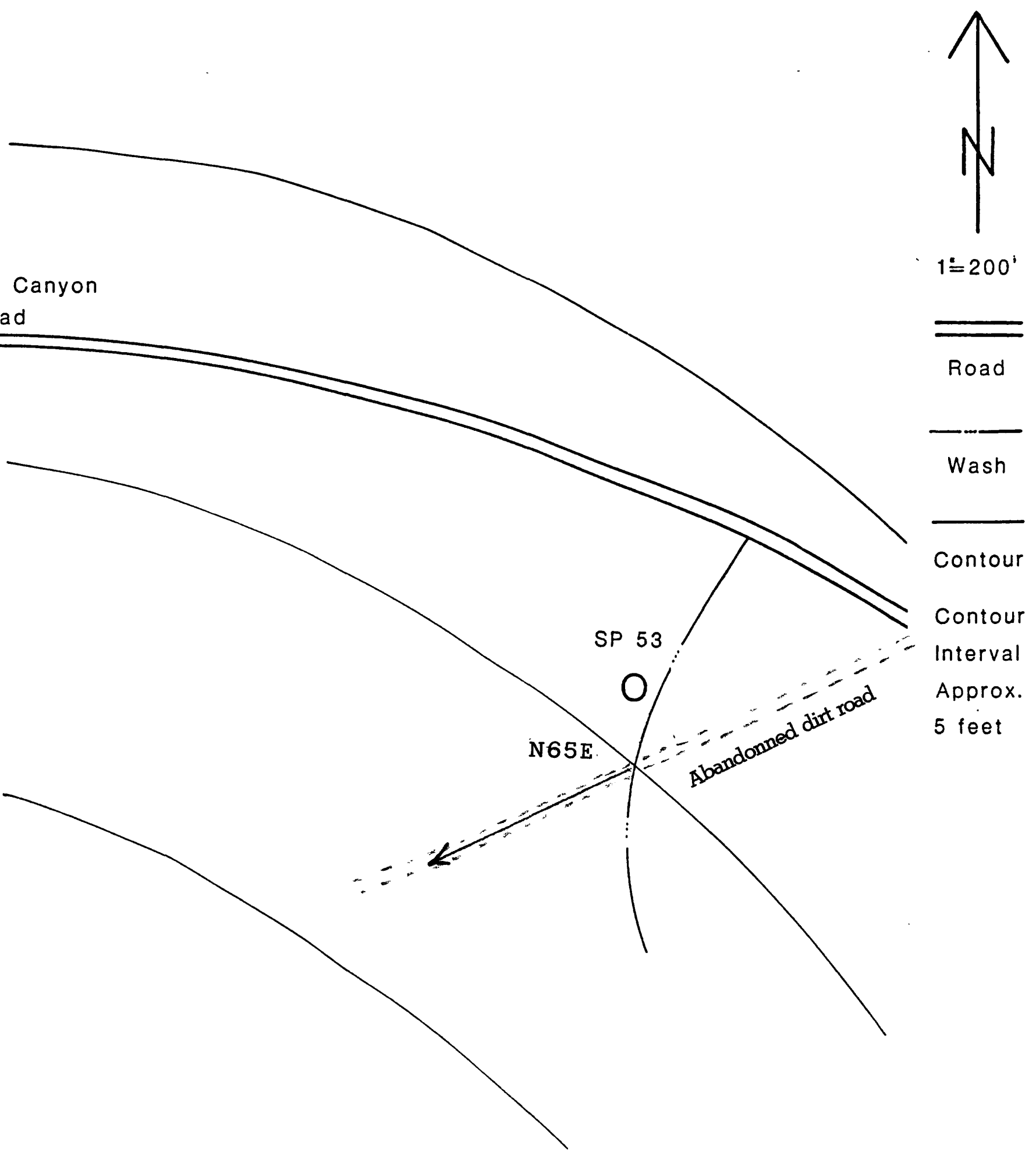

SHOT POINT 53 
STATE OF CALIFORNIA

DEPARTMENT OF WATER RESOURCES

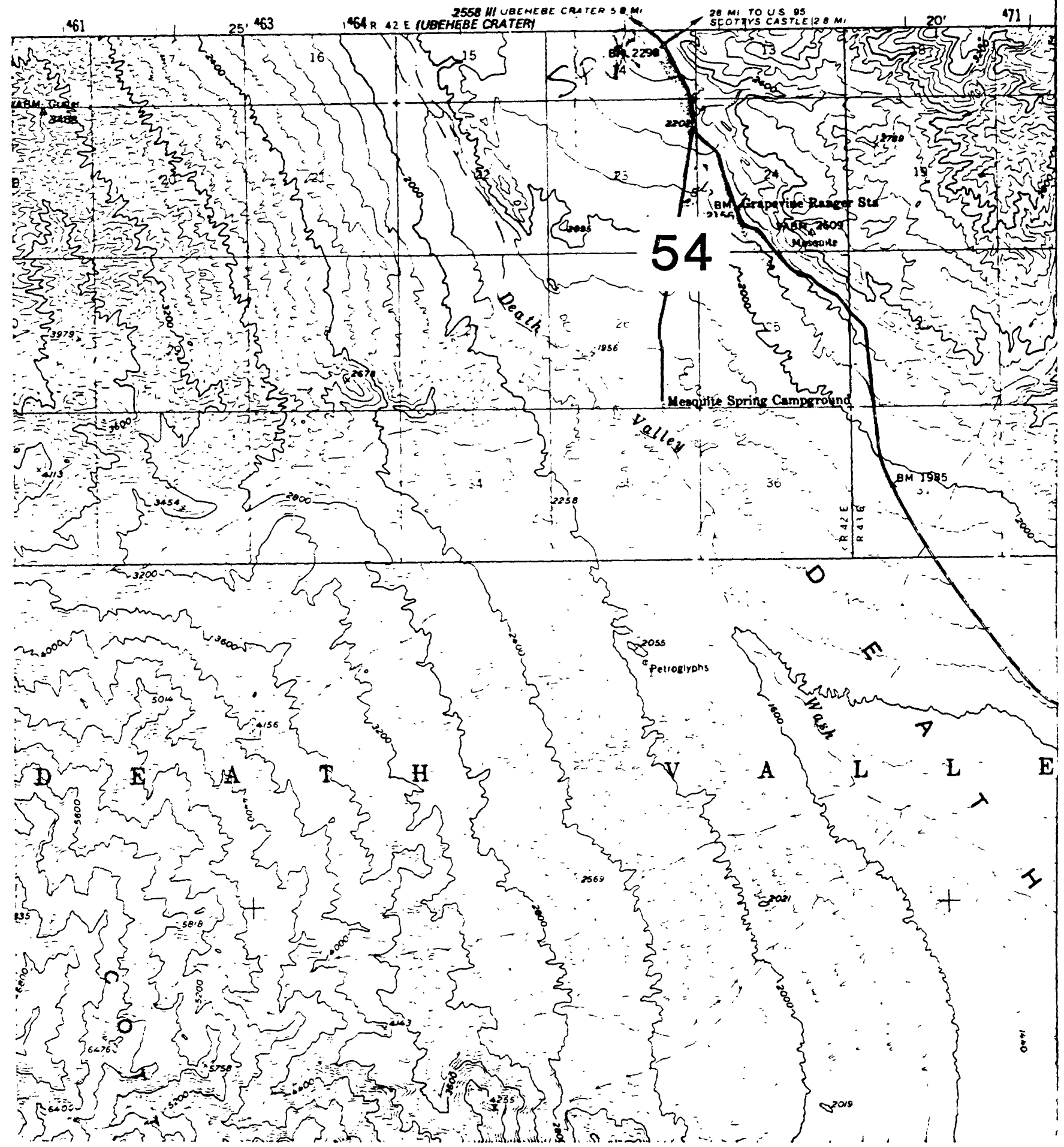



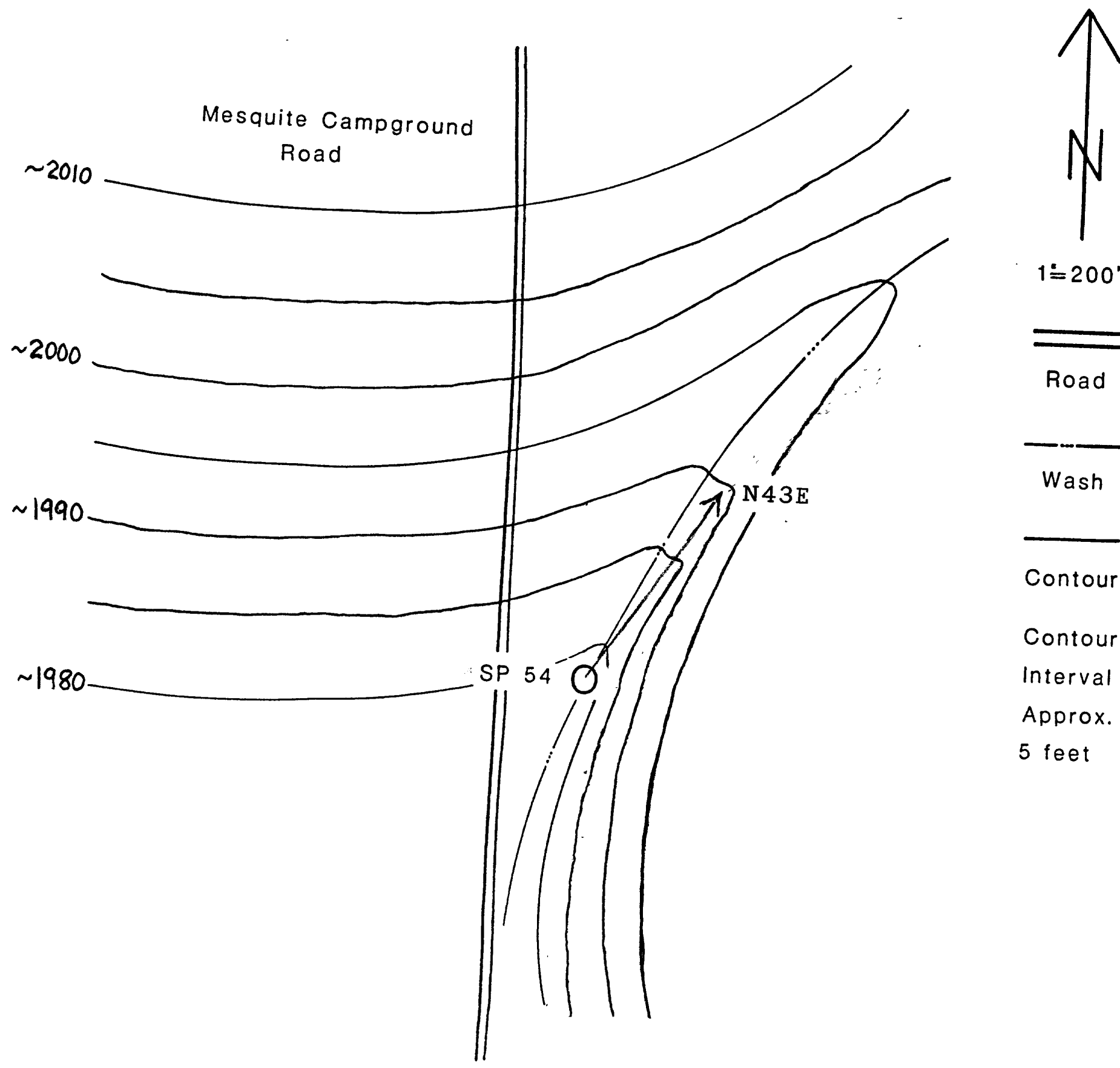

\section{SHOT POINT 54 SITE PLAN}

FIGURE AI-16 (after Criley and Geist, 1987) 
$-34-$

Appendix II:

Data Tables 


\section{SP 33 DATA}

$\begin{array}{cccc}\text { Loc. \# } & \begin{array}{c}\text { Distance } \\ (\mathrm{ft} .)\end{array} & \begin{array}{c}\text { Forwad } \\ (\mathrm{msec})\end{array} & \begin{array}{c}\text { Reverse } \\ (\mathrm{msec})\end{array} \\ 1.0 & 0 & & 70.2 \\ 1.1 & 20 & 13.0 & \\ 2.0 & 30 & 18.1 & 45.0 \\ 2.1 & 45 & 21.9 & \\ 3.0 & 60 & 24.3 & 62.7 \\ 4.0 & 90 & 28.1 & 48.8 \\ 5.0 & 120 & 34.5 & 45.5 \\ 5.1 & 135 & 36.4 & 43.0 \\ 6.0 & 150 & 37.4 & 46.6 \\ 6.1 & 165 & 42.5 & 38.3 \\ 7.0 & 180 & 50.1 & 35.9 \\ 7.1 & 195 & & 33.6 \\ 8.0 & 210 & 54.6 & 27.4 \\ 8.1 & 225 & 58.9 & 28.5 \\ 9.0 & 240 & 58.5 & 24.5 \\ 9.1 & 255 & 59.8 & 22.5 \\ 10.0 & 270 & 64.5 & 18.5 \\ 10.1 & 280 & & 11.5 \\ 10.2 & 290 & & 8.5 \\ 11.0 & 300 & 70.9 & \end{array}$




\section{SP $34 \quad$ DATA}

$\begin{array}{cccc}\text { Loc. \# } & \begin{array}{c}\text { Distance } \\ \text { (ft.) }\end{array} & \begin{array}{c}\text { Forward } \\ \text { (msec) }\end{array} & \begin{array}{c}\text { Reverse } \\ \text { (msec) }\end{array} \\ 1.0 & 0 & & \\ 1.1 & 10 & 7.5 & 83.4 \\ 1.2 & 20 & 12.6 & \\ 2.0 & 30 & 16.8 & 74.5 \\ 2.1 & 45 & 21.9 & 70.9 \\ 3.0 & 60 & 24.4 & 67.1 \\ 3.1 & 75 & 29.4 & \\ 4.0 & 90 & 34.7 & 59.8 \\ 5.0 & 120 & 37.6 & 52.2 \\ 6.0 & 150 & 48.6 & 46.5 \\ 7.0 & 180 & 56.6 & 37.9 \\ 8.0 & 210 & 64.1 & 31.3 \\ 8.1 & 225 & 66.5 & 28.3 \\ 9.0 & 240 & 71.4 & 24.9 \\ 9.1 & 255 & 74.3 & 24.5 \\ 10.0 & 270 & 78.0 & 15.0 \\ 10.1 & 280 & & 11.5 \\ 10.2 & 290 & & 6.9 \\ 11.0 & 300 & 83.6 & \end{array}$




\section{SP 35 DATA}

$\begin{array}{cccccc}\text { Loc. \# } & \begin{array}{c}\text { Distance } \\ (\mathrm{ft} .)\end{array} & \begin{array}{c}\text { Forward } \\ (\mathrm{msec})\end{array} & \begin{array}{c}\text { F. Error } \\ (\mathrm{msec})\end{array} & \begin{array}{c}\text { Reverse } \\ (\mathrm{msec})\end{array} & \begin{array}{c}\text { R. Error } \\ (\mathrm{msec})\end{array} \\ 1.0 & 0 & & & & \\ 2.0 & 30 & 22.7 & 0.5 & 72.0 & 5.0 \\ 3.0 & 60 & 31.2 & 1.0 & 71.5 & 0.8 \\ 3.1 & 80 & 41.6 & 0.5 & & 0.5 \\ 3.2 & 85 & 43.9 & 0.5 & & \\ 4.0 & 90 & 47.0 & 0.2 & 65.9 & 1.0 \\ 4.1 & 100 & 49.8 & 0.5 & & \\ 5.0 & 120 & 52.5 & 0.4 & 61.5 & 0.2 \\ 6.0 & 150 & 56.5 & 2.0 & 59.1 & 0.2 \\ 7.0 & 180 & 59.7 & 1.0 & 55.0 & 0.1 \\ 7.1 & 200 & & & 49.6 & 0.1 \\ 8.0 & 210 & 64.7 & 0.5 & 49.9 & 0.1 \\ 8.1 & 220 & & & 45.9 & 0.1 \\ 9.0 & 240 & 69.7 & 0.1 & 37.4 & 0.1 \\ 10.0 & 270 & 75.0 & 0.5 & 24.5 & 0.1 \\ 11.0 & 300 & 80.0 & 0.5 & & \end{array}$




\section{SP 40 DATA}

$\begin{array}{cccccc}\text { Loc. \# } & \begin{array}{c}\text { Distance } \\ (\mathrm{ft} .)\end{array} & \begin{array}{c}\text { Forward } \\ (\mathrm{msec})\end{array} & \begin{array}{c}\text { F. Error } \\ (\mathrm{msec})\end{array} & \begin{array}{c}\text { Reverse } \\ (\mathrm{msec})\end{array} & \begin{array}{c}\text { R. Error } \\ (\mathrm{msec})\end{array} \\ 1.0 & 0 & & & & 1.0 \\ 1.1 & 10 & 7.4 & & & \\ 1.2 & 20 & 15.0 & & & \\ 2.0 & 30 & 19.1 & & 107.0 & \\ 2.1 & 45 & 27.0 & & 94.0 & \\ 3.0 & 60 & 29.0 & & 89.0 & \\ 4.0 & 90 & 40.2 & & 78.3 & \\ 5.0 & 120 & 49.6 & & 68.3 & \\ 6.0 & 150 & 60.1 & & 60.1 & 0.4 \\ 7.0 & 180 & 68.8 & 0.4 & 50.3 & \\ 8.0 & 210 & 78.6 & & 39.6 & \\ 8.1 & 225 & & & 35.3 & \\ 9.0 & 240 & 88.0 & & 30.3 & \\ 9.1 & 255 & 94.2 & 0.4 & 23.6 & \\ 10.0 & 270 & 99.5 & 0.6 & 19.1 & \\ 10.1 & 280 & & & 12.4 & \\ 10.2 & 290 & & & 8.1 & \\ 11.0 & 300 & 110.0 & 1.0 & & \end{array}$




\section{SP41 DATA}

$\begin{array}{cccccc}\text { Loc. \# } & \begin{array}{c}\text { Distance } \\ (\mathrm{ft} .)\end{array} & \begin{array}{c}\text { Forward } \\ (\mathrm{msec})\end{array} & \begin{array}{c}\text { F. Error } \\ (\mathrm{msec})\end{array} & \begin{array}{c}\text { Reverse } \\ (\mathrm{msec})\end{array} & \begin{array}{c}\text { R. Error } \\ (\mathrm{msec})\end{array} \\ 1.0 & 0 & & & & \\ 1.1 & 10 & 7.4 & & 98.0 & \\ 1.2 & 20 & 13.6 & & & \\ 2.0 & 30 & 14.7 & & 89.0 & 0.3 \\ 2.1 & 45 & 22.4 & 1.0 & 85.7 & \\ 2.2 & 37.5 & 22.0 & 0.5 & 90.0 & 1.0 \\ 3.0 & 60 & 24.2 & & 78.2 & \\ 4.0 & 90 & 32.0 & 1.0 & 76.0 & 0.5 \\ 4.1 & 105 & 44.0 & 1.0 & 67.8 & 0.5 \\ 5.0 & 120 & 45.0 & 1.0 & 62.0 & 1.0 \\ 6.0 & 150 & 55.8 & 0.5 & 51.3 & 0.5 \\ 7.0 & 180 & 64.6 & 0.5 & 42.5 & 0.5 \\ 7.1 & 195 & 71.8 & 0.5 & 42.8 & 0.5 \\ 8.0 & 210 & 73.5 & 0.5 & 34.6 & 0.5 \\ 9.0 & 240 & 85.4 & 0.5 & 23.5 & 0.5 \\ 9.1 & 255 & 85.5 & 0.5 & 20.7 & 0.5 \\ 10.0 & 270 & 89.5 & 0.5 & 19.6 & 0.5 \\ 10.1 & 280 & & & 10.2 & \\ 10.2 & 290 & & & 7.6 & \\ 11.0 & 300 & 97.6 & 0.5 & & \end{array}$


SP42 DATA

$\begin{array}{cccccc}\text { Loc. \# } & \begin{array}{c}\text { Distance } \\ (\mathrm{ft} .)\end{array} & \begin{array}{c}\text { Forward } \\ (\mathrm{msec})\end{array} & \begin{array}{c}\text { F. Error } \\ (\mathrm{msec})\end{array} & \begin{array}{c}\text { Reverse } \\ (\mathrm{msec})\end{array} & \begin{array}{r}\text { R. Error } \\ (\mathrm{msec})\end{array} \\ 1.0 & 0 & & & & \\ 1.1 & 10 & 8.8 & & 49.0 & \\ 1.2 & 20 & 14.8 & & & \\ 2.0 & 30 & 16.0 & & 43.2 & 5.0 \\ 2.1 & 45 & 16.2 & & 39.4 & 5.0 \\ 3.0 & 60 & 25.7 & & 47.8 & \\ 4.0 & 90 & 26.2 & & 45.3 & \\ 5.0 & 120 & 26.6 & & 40.3 & \\ 6.0 & 150 & 28.0 & & 34.6 & \\ 7.0 & 180 & 32.8 & & 32.8 & \\ 8.0 & 210 & 37.8 & & 24.8 & \\ 9.0 & 240 & 41.0 & 3.0 & 18.6 & 4.0 \\ 9.1 & 255 & 41.8 & & 20.8 & 5.0 \\ 10.0 & 270 & 43.0 & & 16.2 & \\ 10.1 & 280 & & & 10.8 & \\ 10.2 & 290 & & & 9.8 & 3.0 \\ 11.0 & 300 & 48.3 & & & \end{array}$




\section{SP53 DATA}

$\begin{array}{cccccc}\text { Loc. \# } & \begin{array}{c}\text { Distance } \\ (\mathrm{ft} .)\end{array} & \begin{array}{c}\text { Forward } \\ (\mathrm{msec})\end{array} & \begin{array}{c}\text { F. Error } \\ (\mathrm{msec})\end{array} & \begin{array}{c}\text { Reverse } \\ (\mathrm{msec})\end{array} & \begin{array}{c}\text { R. Error } \\ (\mathrm{msec})\end{array} \\ 1.0 & 0 & & & 67.0 & \\ 1.1 & 10 & 6.9 & & & \\ 1.2 & 20 & 12.2 & & & \\ 2.0 & 30 & 14.3 & & 61.9 & \\ 2.1 & 45 & 18.6 & & 60.5 & \\ 2.2 & 52.5 & 23.8 & & & \\ 3.0 & 60 & 28.2 & & 58.6 & \\ 3.1 & 75 & 30.7 & & 51.3 & \\ 4.0 & 90 & 32.7 & & 54.0 & 1.2 \\ 5.0 & 120 & 37.6 & & 52.9 & \\ 6.0 & 150 & 44.2 & & 47.9 & \\ 7.0 & 180 & 44.8 & & 39.8 & \\ 8.0 & 210 & 56.3 & & 37.6 & \\ 8.1 & 225 & 52.4 & & 36.9 & \\ 9.0 & 240 & 58.6 & & 27.6 & \\ 9.1 & 255 & 56.8 & 2.0 & 22.4 & \\ 10.0 & 270 & 62.0 & & 15.2 & \\ 10.2 & 277.5 & 65.0 & & 13.5 & \\ 10.1 & 285 & 69.2 & & 14.8 & 1.5 \\ 11.0 & 300 & 70.4 & & 8.5 & 2.0 \\ 11.1 & 310 & & & 6.1 & 0.5 \\ 11.2 & 320 & & & 6.7 & \\ 12.0 & 330 & 68.0 & & & \end{array}$




\section{SP54 DATA}

$\begin{array}{cccccc}\text { Loc. \# } & \begin{array}{c}\text { Distance } \\ (\mathrm{ft} .)\end{array} & \begin{array}{c}\text { Forward } \\ (\mathrm{msec})\end{array} & \begin{array}{c}\text { F. Error } \\ (\mathrm{msec})\end{array} & \begin{array}{c}\text { Reverse } \\ (\mathrm{msec})\end{array} & \begin{array}{c}\text { R. Error } \\ (\mathrm{msec})\end{array} \\ 1.0 & 0 & & & & \\ 1.1 & 10 & 9.3 & 0.5 & 105.5 & 9.0 \\ 1.2 & 20 & 15.0 & 0.5 & & \\ 2.0 & 30 & 17.7 & 0.5 & 99.0 & 10.0 \\ 2.1 & 45 & 24.6 & 0.5 & 97.7 & 8.0 \\ 3.0 & 60 & 33.2 & 0.5 & 101.0 & 2.0 \\ 4.0 & 90 & 48.5 & 0.5 & 91.7 & 0.5 \\ 5.0 & 120 & 63.6 & 0.5 & 81.8 & 0.5 \\ 6.0 & 150 & 73.7 & 0.5 & 69.6 & 0.5 \\ 7.0 & 180 & 82.3 & 0.5 & 61.3 & 0.5 \\ 8.0 & 210 & 91.3 & 0.5 & 45.8 & 0.5 \\ 9.0 & 240 & 103.5 & 0.5 & 33.8 & 0.3 \\ 9.1 & 255 & 106.3 & 1.0 & 27.8 & 0.3 \\ 10.0 & 270 & 108.5 & 0.5 & 19.3 & \\ 10.1 & 280 & 109.0 & 0.5 & 14.4 & \\ 10.2 & 290 & 110.8 & 0.3 & 8.5 & 0.5 \\ 11.0 & 300 & 111.8 & 0.3 & & \end{array}$

